
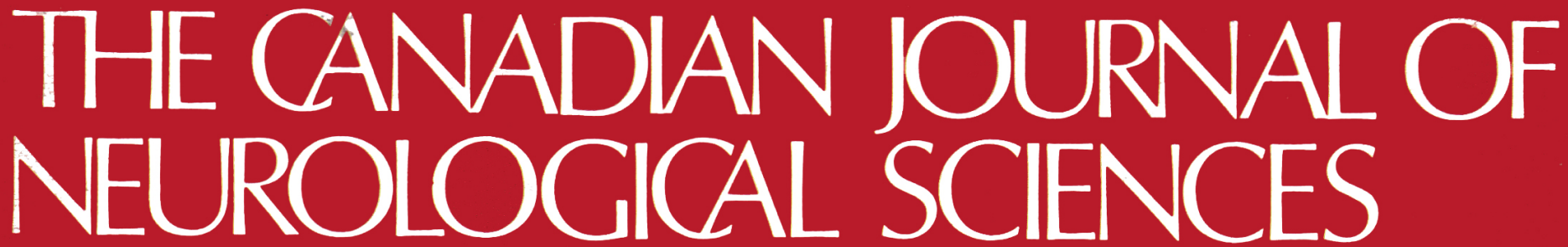

LE
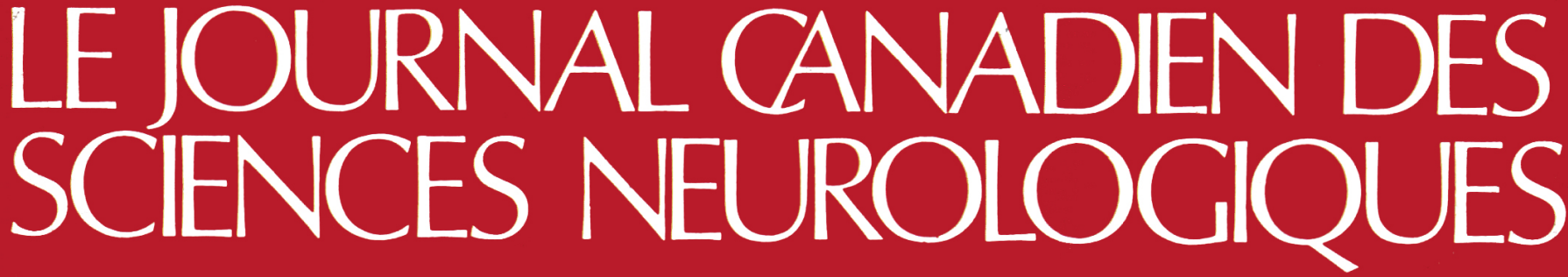

Goose Quills and Burr Holes Frank Turnbull

The Neurological Complications of Brucellosis F. A. Larbrisseau, E. Maravi,
F. Auilera, J. M. Martinez-Lage

Automatic Quantitative Analysis of the Electromyogram in Partially Denervated Distal Muscles:

Comparison with Motor Unit Counting ................ A. J. McComas and R. E. P. Sica

Clinical Efficacy of Valproic Acid in Relation to Plasma Levels ....... J. Bruni, B. J. Wilder. L. J. Willmore, H. J. Villarreal, M. Thomas, L. E. M. Crawford

A Comparative Study of $b$ - and $d$ - Waves of the Electroretinogram in Frogs

(Rana Catesbeiana) .......................... S. Molotchnikoff and F. Guertin-Laurin

Accumulation and Removal of $\mathrm{Hg}^{203}$ in Different Regions of the Rat Brain . R. F. Butterworth, $M$. Gonce and A. Barbeau

Ouabain Induced Stereotyped Behavior in Rats D. L. W. Davidson, R. F. Butterworth, F. Belanger, A. Barbeau

Ouabain Induced Seizures: Site of Production and Response

to Anticonvulsants .............. Duncan L. W. Davidson, Yasuo Tsukada, Andre Barbeau

Increased Dependence on Visual Intormation for Movement Control in Patients

with Parkinson's Disease ..................... J. D. Cooke, J. D. Brown and V. B. Brooks

Functional Implications of Changes in the Senescent Brain: A Review .. Charles H. M. Beck

Virology and Histopathology of the Trigeminal Ganglia of

Americans and Japanese ........... K. G. Warren, Z. Wroblewska, H. Okabe, S. M. Brown, D. H. Gilden, H. Koprowski, L. B. Rorke, J. Subak-Sharpe, and T. Yonezawa

Pseudotumor Cerebri F. L. Moffat

Alterations of Membrane Phosphorylation in Erythrocyte Membranes from Patients with

Duchenne Muscular Dystrophy ......... J. D. Vickers, A. J. McComas, and M. P. Rathbone

Cerebral Tissue Response to Electrode Implantation Ronald F. Dodson, L. W-F. Chu, N. Ishihara

Case Report and Ultrastructural Study of Intracranial

Embryonal Carcinoma .......... Gershon Ejeckam, Margaret G. Norman and Leslie P. Ivan

Notices and Books 


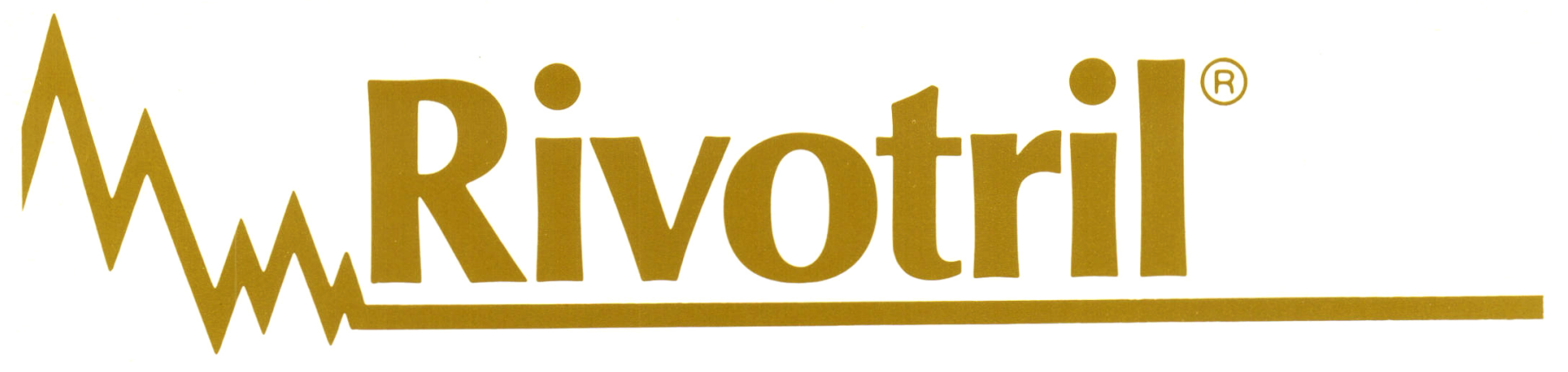

\section{a new oral anticonvulsant from 'Roche' research}

Effect of RIVOTRIL on seizure frequency

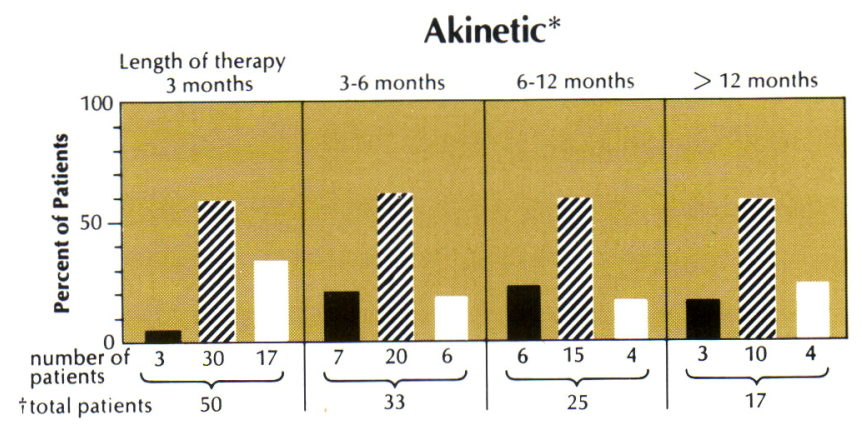

Myoclonic with and without Hypsarrhythmia*

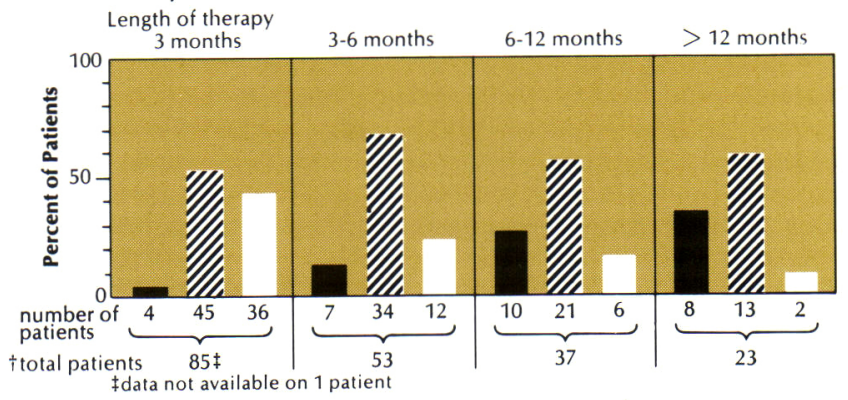

RIVOTRIL, with specific and potent anticonvulsant properties, is a new benzodiazepine in the same family as Librium ${ }^{\circledR}$, Valium $^{\circledR}$ and Dalmane ${ }^{\circledR}$ Roche $^{\circledR}$. It is therefore characterized by the same high degree of safety and efficacy.

- used alone or as an adjunct, RIVOTRIL can reduce the frequency and/or severity of akinetic, myoclonic and petit mal variant (Lennox-Gastaut syndrome) seizures.

- it may be of value as principal medication in petit mal where succinimide therapy has failed.

- the most frequently noted side effects, drowsiness and ataxia, generally are dose related and can often be controlled by dosage adjustments.
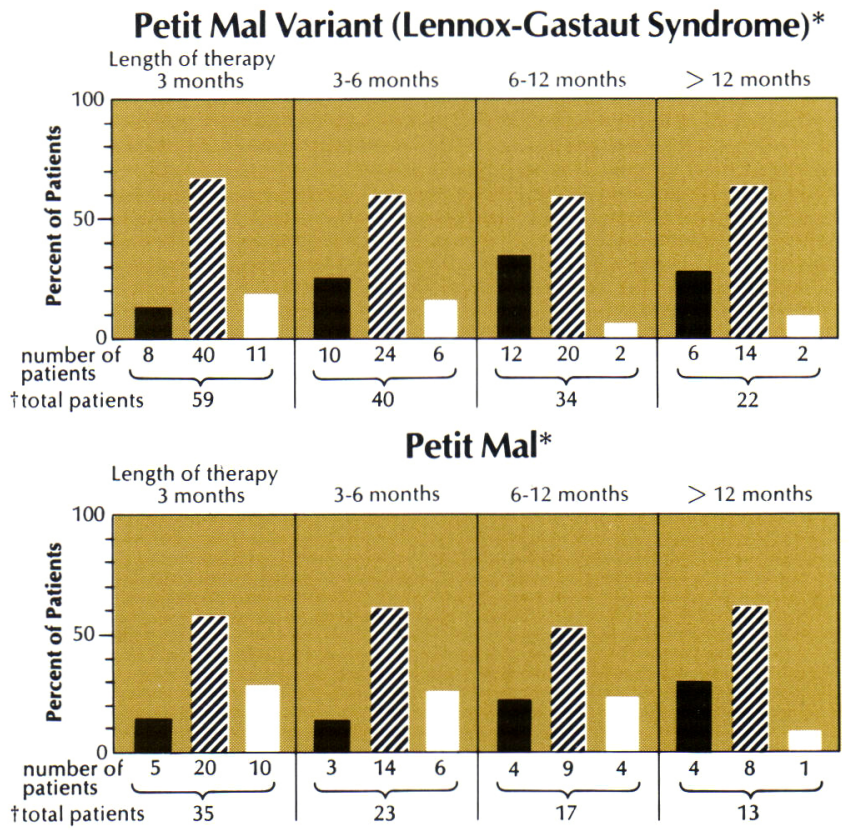

Seizures $100 \%$ controlled

$\square$ Seizures better than $50 \%$ reduced in frequency $\square$ Seizures uncontrolled

* Data on file, Hoffimann-La Roche Limited

†Patients dropped from the study for a variety of reasons

as well as those treated for less than 12 months account for

the decrease in total patient population. 


\section{An important aid in the management of minor seizures}

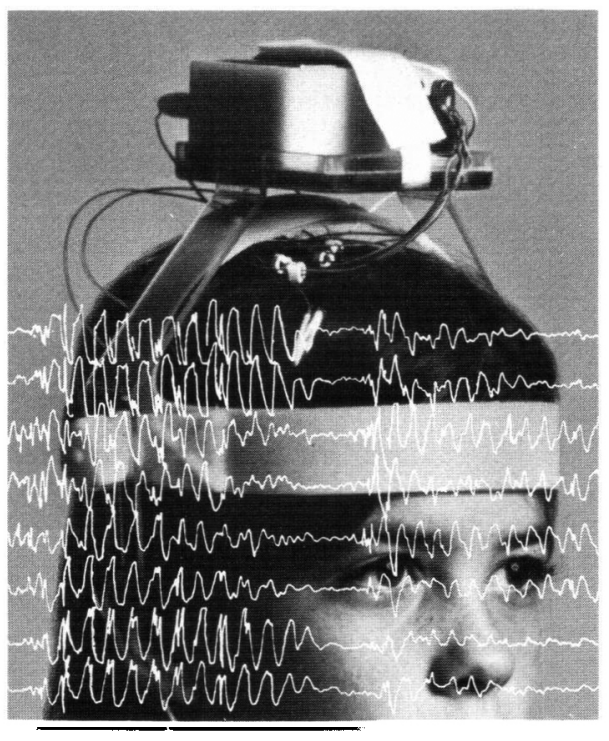

Noninvasive EEG telemetry device used to monitor patients in studies evaluating RIVOTRIL.

Rivotril ${ }^{\circledR}$ (clonazepam)

Brief Prescribing Information

Action

RIVOTRIL is a benzodiazepine and has sedative, hypnotic, and anticonvulsant properties characteristic of this class of drugs. As an anticonvulsant, it decreases the frequency, amplitude, duration, and spread of discharges in minor motor seizures and suppresses the spike-and-wave discharge in absence seizures.

The maximum blood level of clonazepam after a single oral dose is reached within 1 to 2 hours. The half-life of clonazepam is approximately 18 to 50 hours, and the main route of excretion is in the urine.

Indications

RIVOTRIL has been found useful when used alone or as an adjunct in the management of myoclonic and akinetic seizures and petit mal variant (Lennox-Gastaut syndrome).

RIVOTRIL may also be of value in patients with petit mal (absence spells) who have failed to respond satisfactorily to succinimides. If a loss of anticonvulsant effect occurs, dosage adjustment may re-establish efficacy in some cases.

Contraindications

In patients with:

- known hypersensitivity to benzodiazepines

- significant liver disease

- narrow-angle glaucoma

Warnings

RIVOTRIL should be used by women of child-bearing potential only when the expected benefits to the patient warrant the possible risks to the fetus. Women who become pregnant should consult their physician promptly with regard to continuing antiepileptic medication.
Mothers receiving RIVOTRIL should not breast feed their infants. Because adverse effects may possibly become apparent only after years of administration, a risk/benefit consideration of long-term use of RIVOTRIL is important in pediatric patients.

Precautions

The use of multiple anticonvulsants may increase CNS-depressant effects and the dosage of each drug may need adjustment to obtain the optimum effect.

To avoid precipitation of status epilepticus, abrupt withdrawal of RIVOTRIL must be avoided. Substitution of a nother antir.onvulsant may be indicated during RIVOTRIL withdrawal.

In a very few patients, RIVOTRIL may cause a paradoxical increase in seizure activity or new types of seizures. RIVOTRIL may precipitate the onset of grand mal or increase its incidence. The addition of appropriate anticonvulsants or an increase in their dosage may be necessary. Patients should be cautioned against engaging in hazardous occupations requiring complete mental alertness, and should al so be warned against the concomitant use of alcohol or other CNS-depressant drugs.

Patients who may be prone to increase drug dosage on their own should be monitored carefully when receiving RIVOTRIL, as benzodiazepines have produced habituation, dependence, and withdrawal symptoms. RIVOTRIL should be administered with caution to patients with impaired renal function.

Periodic liver function tests and blood counts are recommended during long-term therapy with RIVOTRIL.

Treatment with RIVOTRIL should be instituted with caution in patients with chronic respiratory disease, because of the possibility of hypersecretion in the upper respiratory passages.

Adverse reactions

Drowsiness has occurred in $50 \%$ and ataxia in $30 \%$ of the patients treated with RIVOTRIL. In some cases these effects have diminished with time. Behaviour problems have been noted in approximately $25 \%$ and increased salivation in $7 \%$ of the patients.

Please see product monograph for a complete list of other possible adverse reactions.

Dosage and administration

Dosage of RIVOTRIL must be determined for each patient according to clinical response and tolerance. Dosage depends, above all, on the age of the patient.

The daily requirement should be given in 2 or 3 divided doses. If the doses are not equal, the larger dose should be given before retiring.

Children up to 10 years or $30 \mathrm{~kg}$ : In order to minimize drowsiness, the initial dosage should usually be between 0.01 and $0.03 \mathrm{mg} / \mathrm{kg} /$ day and must not exceed $0.05 \mathrm{mg} / \mathrm{kg} / \mathrm{day}$.

The dosage should be increased by 0.25 to $0.5 \mathrm{mg} /$ day every third day, unless seizures are controlled or side effects intervene, until a maintenance dosage of 0.1 to $0.2 \mathrm{mg} / \mathrm{kg} /$ day has been reached. Adults: The initial dosage should not exceed $1.5 \mathrm{mg} /$ day.

The dosage should be increased by 0.5 to $1 \mathrm{mg}$ every third day, until seizures are controlled or side effects intervene. The recommended maintenance dosage for adults is 8 to $10 \mathrm{mg} /$ day in 3 divided doses. Dosages in excess of $20 \mathrm{mg} /$ day should be administered with caution. Whenever RIVOTRIL is added to an anticonvulsant regimen, it should be borne in mind that the use of multiple anticonvulsants may result in increased depressant adverse effects.

Supply

Scored tablets, 0.5 and $2 \mathrm{mg}$. Bottles of 100.

- Reg. Trade Marks

Full prescribing information on request. Vaudreuil, Quebec 


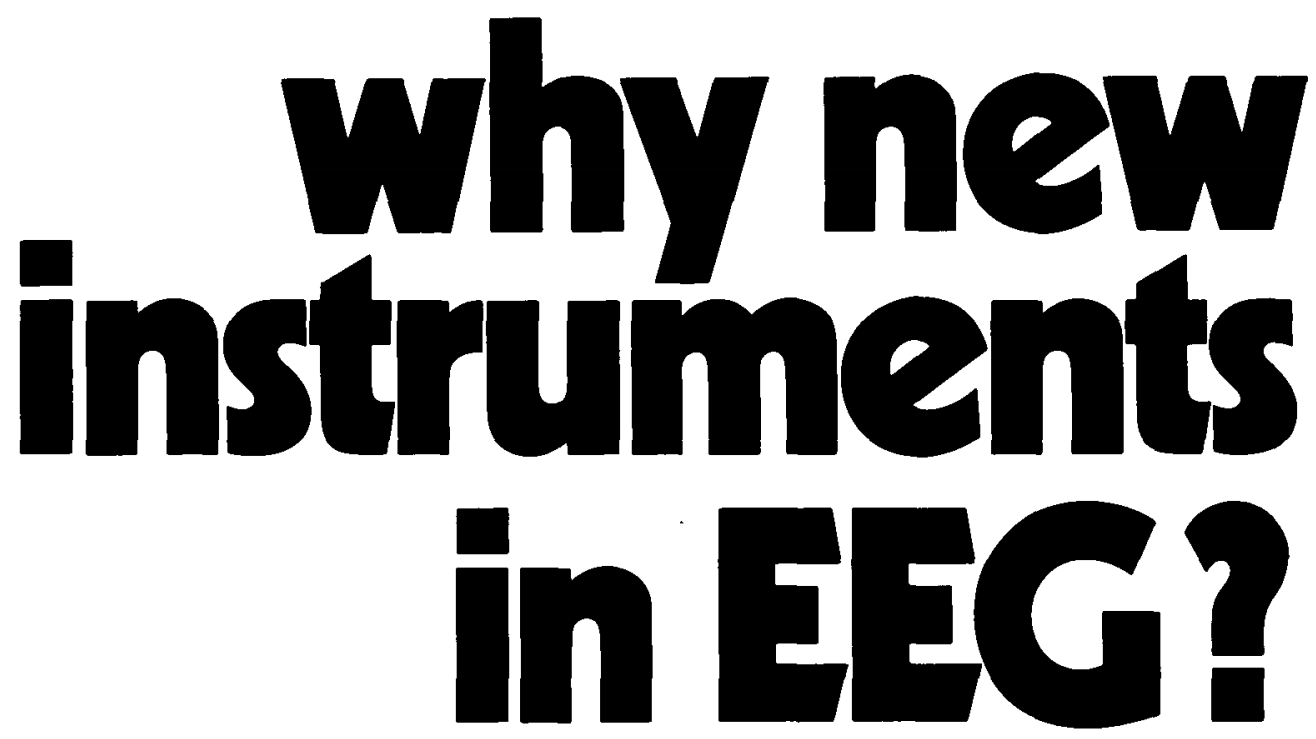

Because you asked for them. In reality, doctors and technologists have been the initiators for changes in instrumentation. As your needs have changed, so have your instruments.

In the mid-1950's, you wanted more reliable instruments. We introduced solid state electronics which made tube-type instruments obsolete. It was the first really innovative step forward in EEG electronics in many years.

In the early 1970's, you asked for small, mobile EEG's that could operate anywhere in a hospital or fit comfortably in an office. Again, we responded, and the Accutrace ${ }^{\text {TM }}$ EEG was introduced.

In more recent years, we have heard other requests:

"Why can't I change the presets myself?"

"When will I have a mobile 16- or 20-channel EEG?"

"Why can't I visually verify my presets?"

"When will patient isolation be standard so I can use the instrument on anyone, anywhere?"

"When will I have an instrument I can service myself?"

"Why can't I economically expand the number of channels on my instrument?"

All of these ideas are logical steps in the evolution of EEG instruments, but they are no longer just ideas; they are realities in the new ACCUTRACE EEG.

The following instrument decriptions are just hints of what the actual instruments are like. All of these things are possible because once again Beckman Instruments is in the forefront by using the very latest in microprocessing electronics. At Beckman Instruments, Leadership Through Innovation isn't simply a slogan. It's a reality.

\section{Accutrace $^{\text {'m }}$ Model 200 EEG}

The totally mobile Accutrace Model 200 offers from 8 to 20 channels of EEG. That's right, now you can have a full 20 channels of information. But if you only need 8,10 , or even 18 channels today, it's great to know that you can economically expand the unit to as many as 20 channels tomorrow without buying a new instrument!

Patient isolation is no longer a problem because the Accutrace offers it as a standard feature. We believe patient isola-

tion isn't something you should have to ask for; it is something you should expect.

A push-button electrode entry system allows the operator to easily enter electrodes manually. A digital display readout permits easy verification of override and preset values. As a double check, we have also incorporated a lighted head display. This visually verifies which electrodes are being used in either preset montage or override montage. It's a valuable means of verifying electrodes.

Another area of concern has always been presets. No longer must you purchase a dedicated unit limited to one set of montages. Now you can have programmable presets and change your presets at will. Sound good so far? We've even gone a few steps further.

Now at the touch of a single button, the instrument's autodiagnostic system surveys its components. Within seconds, the digital readout identifies the number of any malfunctioning module. You don't search for a problem; the instrument does it for you. Again, it's the microprocessor which surveys the electronics, eliminating time-consuming, step-by-step checks of the circuitry. It saves the EEG owner time and money.

In addition, the Accutrace 200 has an optional auto verification system which codes the patient number, preset number, and signal filtering information on each tracing.

You must admit that everything we've described makes the Accutrace sound like a dream instrument, which it is, but wait until you sit down to actually run a record. We have eliminated $90 \%$ of the surface switches and replaced them with a silent, touch-sensitive control panel for the ultimate in simplicity and convenience.

\section{Accutrace $^{\text {rw }}$ Model 100 EEG}

The Accutrace Model 100 EEG is a compact 8- or 10-channel mobile unit which has features not found on comparable units manufactured today. For example, the Model 100 comes standard with patient isolation and a simplified control panel for operator convenience. The instrument features a manual diagnostic system for troubleshooting, which allows the operator to devote more time to the patient. The Model 100 instruments are everything you've come to expect in an Accutrace, plus the safety and convenience not found on any other instrument except the new Accutrace Model 200's. 


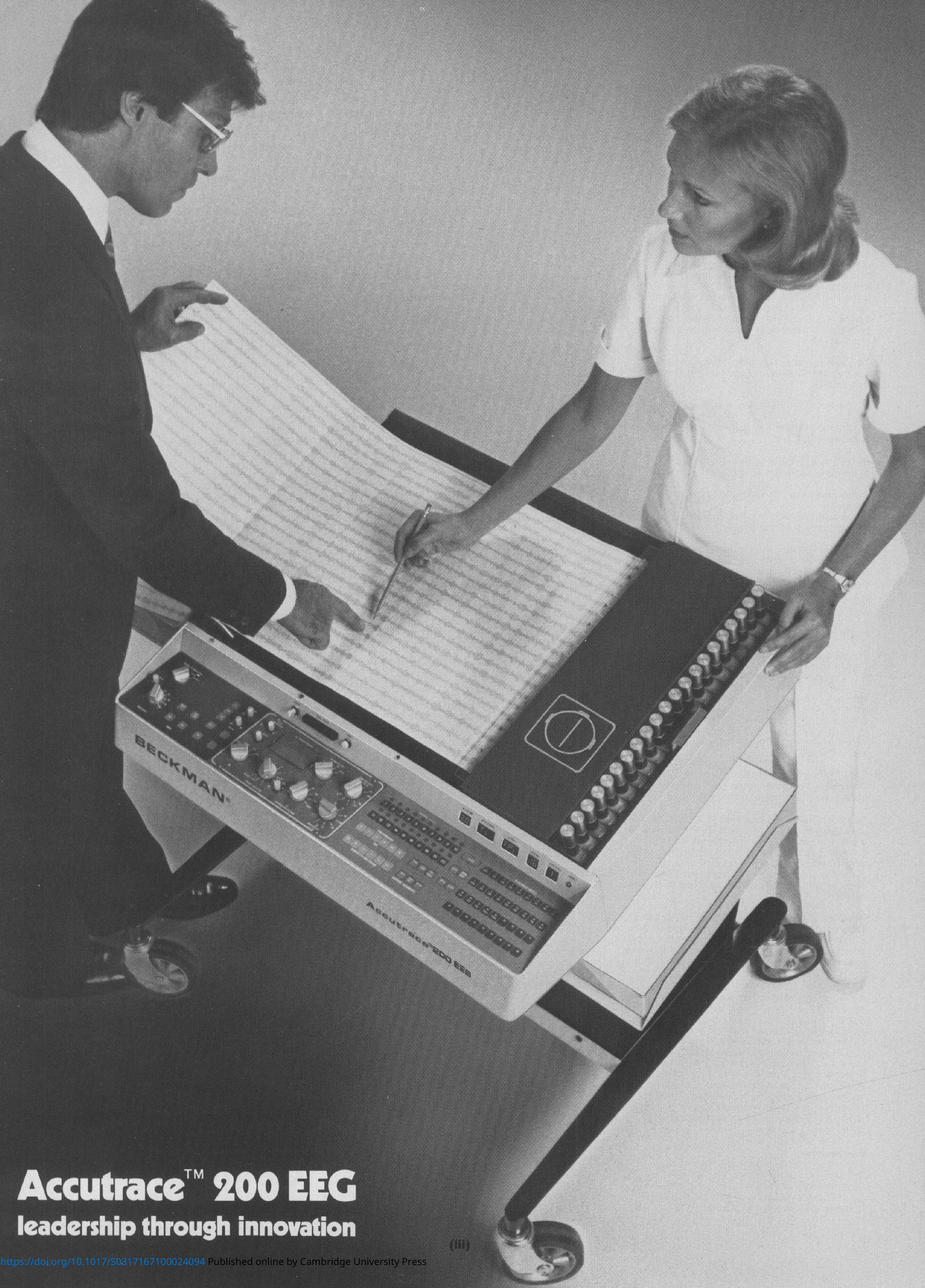




\section{Tegretol}

\section{Briel prescribing information}

Tegretolo $200 \mathrm{mg}$

Carbamazepine

Indications and clinical use

A. Trigeminal Neuralgia:

Tegretol is indicated for the symptomatic relief of pain of trigeminal neuralgia only during periods of exacerbation of true or primary trigeminal neuralgia (tic douloureux). It should not be used preventively during periods of remission. In some patients, Tegretol has relieved glossopharyngeal neuralgia. For patients who fail to respond to Tegretol, or who are sensitive to the drug. recourse to other accepted measures must be considered.

Tegretol is not a simple analgesic and should not be used to relieve trivial facial pains or headaches.

\section{B. Tegretol has been found useful in}

1) the management of psychomotor (temporal lobe) epilepsy and

2) as an adjunct, in some patients with secondary or partial epilepsy with complex

symptomatology or secondarily generalized seizures,

when administered in combination with other antiepileptic medication.

Tegretol is essentially ineffective in controlling petit mal, minor motor, myoclonic and predominantly unilateral seizures, and does not prevent the generalization of epileptic discharge.

\section{Contraindications}

Tegretol should not be administered to patients with a history of hepatic disease or serious blood disorder.

Tegretol should not be administered immediately before, in conjunction with, or immediately afte a monoamine oxidase inhibitor. When it seems desirable to administer Tegretol to a patient who has been receiving an MAO inhibitor, there should be as long a drug-free interval as the clinical condition allows, but in no case shc clinical condition allows, but in no case should this be less than 14 days. Then the dosage of Tegretol should
very gradually.

Safe use in pregnancy has not been established. Therefore, Tegretol should not be administered during the first three months of pregnancy.

Tegretol should not be given to women of childbearing potential unless, in the opinion of
the physician, the expected benefits to the patient outweigh the possible risk to the foetus patient outweigh the possible risk to the
(See Reproductive Studies). Because of (See Reproductive Studies). Because of demonstrated toxicity in nursing animals
Tegretol should not be administered to nursing mothers.

Because of the similarity of chemical structure, Tegretol should not be administered to patients with known hypersensitivity to any of the tricyclic compounds, such as amitriptyline, trimipramine. imipramine, or their analogues or metabolites.

\section{Warnings}

Although reported infrequently, serious adverse effects have been observed during the use of Tegretol. Agranulocytosis and aplastic anemia have occurred in a few instances with a fatal outcome. Leucopenia, thrombocytopenia a fatal outcome. Leucopenia, thrombocytopen and hepatoceliular and cholestatic jaund have also been reported. It is, therefore,
important that Tegretol should be used carefully important that Tegretol should be used caref and close clinical and frequent laboratory supervision should be maintained throughout treatment in order to detect as early as p
signs and symptoms of a possible blood dyscrasia.

\section{Precautions}

Monitoring of Haematological and Other Adverse Reactions:

Complete blood studies, including platelet counts, and evaluation of hepatic and renal function and urinalysis should be carried out
A before treatment is instituted. Careful clinical and laboratory supervision should be maintained throughout treatment, including frequent performance of complete blood counts, in order to detect any early signs or symptoms of blood dyscrasia. Should any signs or symptoms or abnormal laboratory findings suggestive of blood dyscrasia or liver disorder occur, Tegretol should be immediately discontinued until the case is carefully reassessed.

Urinary Retention and Increased Intraocular Pressure:

Because of its anticholinergic action, Tegretol should be given cautiously, if at all, to patients with increased intraocular pressure or urinary retention. Such patients should be followed closely while taking the drug.

Occurrence of Behavioural Disorders

Because it is closely related to the other tricyclic drugs, there is some possibility that Tegretol might activate a latent psychosis, or, in elderly patients, produce agitation or confusion, especially when combined with other drugs. Caution should also be exercised in alcoholics.

Use in Patients with Cardiovascular Disorders Tegretol should be used cautiously in patients with a history of coronary artery disease, organic heart disease, or congestive failure.

Driving and Operating Hazardous Machinery: Because dizziness and drowsiness are possible side effects of Tegretol, patients should be warned about the possible hazards of operating machinery or driving automobiles.

\section{Adverse reactions:}

The reactions which have been most frequently reported with Tegretol are drowsiness, unsteadiness on the feet, vertigo, dizziness, gastrointestinal disturbances, and nausea. These reactions usually occur only during the initial phase of therapy. They have rarely necessitated discontinuing Tegretol therapy, and can be minimized by initiating treatment at a low dosage.

The more serious adverse reactions observed are the haematologic, hepatic, cardiovascular and dermatologic reactions, which require discontinuation of therapy.

The following adverse reactions have been reported:

\section{Haematological reactions:}

Transitory leucopenia, eosinophilia, leucocytosis, thrombocytopenic purpura, agranulocytosis, macrocytic anemia and aplastic anemia. In a few instances, deaths have occurred.

Hepatic disturbances

During the long-term administration of Tegretol abnormalities in liver function tests and cholestatic or hepatocellular jaundice have been observed.

Dermatological reactions:

The following reactions occurred during treatment with Tegretol: skin sensitivitiy reactions and rashes, erythematous rashes, pruritic eruptions, urticaria, photosensitivity, pigmentary changes, neurodermatitis and in rare cases Stevensneurodermatitis and in rare cases Stevensalopecia, diaphoresis, erythema multiforme, alopecia, diaphoresis, erythema multiforme,
erythema nodosum, and aggravation of disseminated lupus erythematosus.

\section{Neurological reactions}

The reactions reported as occurring during treatment with Tegretol include vertigo somnolence, disturbances of coordination, confusion, headache, fatigue, blurred vision, transient diplopia and oculomotor disturbances speech disturbances, abnormal involuntary movements and increase in motor seizures. In addition, peripheral neuritis and paresthesia, depression with agitation, talkativeness nystagmus, and tinnitus have been reported but only very rarely. There have been some reports of paralysis and other symptoms of cerebral arterial insufficiency but no conclusive relationship to the administration of Tegretol relationship to the admil
could be established.

\section{Cardiovascular systems:}

Recurrence of thrombophlebitis in patients with a prior history of thrombophlebitis, congestive heart failure, aggravation of hypertension. hypotension, syncope and collapse, edema, aggravation of coronary artery disease. Some of these complications have resulted in fatalities.
Other cardiovascular complications (including myocardial infarction and arrhythmia) have been associated with other tricyclic compounds.

Whether all these complications are drug-related is not known at this time.

\section{Genitourinary reactions:}

Urinary frequency, acute urinary retention, oliguria with elevated blood pressure, and impotence. Elevation of BUN, albuminuria and glycosuria also have been observed.

Digestive tract:

Disturbances associated with Tegretol therapy have included nausea, vomiting, gastric or abdominal discomfort, diarrhoea, anorexia and dryness of the mouth and throat, glossitis and stomatitis.

Eyes:

There is no conclusive evidence that Tegretol produces pathological changes in the cornea. lens or retina. However, it should be recognized that many phenothiazines and related drugs have been shown to cause eye changes. By analogy, periodic eye examinations, including slit-lamp fundoscopy and tonometry, are recommended.

Other reactions reported during treatment with Tegretol include fever and chilis, lymphadenopathy, aching joints and muscles, leg cramps and conjunctivitis.

\section{Dosage and administration}

Use in psychomotor and other secondary or partial seizures:

A low initial daily dosage with a gradual increase in dosage is advised. Dosage should be adjusted to the needs of the individual patient.

\section{Initially:}

100 to $200 \mathrm{mg}$ once or twice a day depending on the severity of the case and previous therapeutic history. The initial dosage is progressively increased, until the best response is obtained, up to $600 \mathrm{mg}$ daily. The usual optima dosage is $600 \mathrm{mg}$ daily, but occasionally dosages up to 800 to $1000 \mathrm{mg}$ have been used for short periods. As soon as disappearance of seizures has ben obtained and maintained, dosage should be reduced very gradually until a minimum effective dose is reached.

Use in trigeminal neuralgia:

The initial daily dosage should be small; $200 \mathrm{mg}$. taken in two doses of $100 \mathrm{mg}$ each is recommended. The total daily dosage can be increased by $200 \mathrm{mg}$ per day until relief of pain is obtained. This is usually achieved at a dosage between 200 and $800 \mathrm{mg}$ daily, but occasionally up to $1200 \mathrm{mg}$ per day may be necessary. As soon as relief of pain has been obtained and maintained progressive reduction in dosage should be attempted until a minimum effective dosage is reached. Because trigeminal neuralgia is characterized by periods of remission, attempts should be made to reduce or discontinue the use of Tegretol at intervals of not more than 3 months, depending upon the individual clinical course.

Prophylactic use of the drug in trigeminal neuralgia is not recommended.

Tegretol should be taken in two or three divided doses daily, with meals whenever possible.

\section{Dosage forms}

Tegretol is available as a $200 \mathrm{mg}$ white, round, single-scored tablet, engraved with signet.

Availability

Bottles of 50 and 500 tablets. Protect from moisture.

\section{Reforences}

1. Livingston, S.: "Comprehensive Management of Epilepsy in Infancy Childhood and Adolescence". Springfield, Charles C. Thomas, 1972

2. Braunholer, J.: Med Klin. 60:343-348, 1965

Lerman, P., and Kivity-Ephraim, S.: Carbamazepine Sole Anticonvulsant for Focal Epilepsy of Childhood. Epilepsia, 15:229-234, 1974. New York

Full information is available on request.

\section{Geigy}

Dorval, P.Q., H9S 1B1 


\section{Editorial Advisory Board}

\author{
C. Miller Fisher \\ Boston
}

\section{Editorial Board}

Murray L. Barr

London

Donald W. Baxter

Montreal

Claude Bertrand

Montreal

Guy Courtois

Montreal

John G. Humphrey

Toronto

Alan J. McComas

Hamilton

\section{Associate Editor}

Andre Barbeau

Montreal

THE EDITORIAL BOARD wishes to publish original work in the basic and clinical neurosciences on the understanding that it has not been and will not be published elsewhere. Review articles on timely subjects will be accepted. Manuscripts must be in duplicate including illustrations. One of the copies must be the original, ribbon copy. Manuscripts should be typed double spaced, on white paper.

Papers will be accepted in French or English. All papers should be accompanied by a short résumé in both languages. The résumé translation will be done by the editorial board if requested.

Papers should be identified only by the full name of the author, or authors, and the name of the place in which the work was done.

ILLUSTRATIONS: Photographs should be unmounted on glossy paper and show magnification scale. They should be marked on the back with figure number, title of paper and name of author.

Diagrams should be in India ink and large enough to be informative after reduction.

All illustrations should be referred to as figures, numbered consecutively, not included in the body of the text and

\author{
J. C. Richardson \\ Toronto \\ Donald B. Tower \\ Bethesda
}

\author{
Douglas A. McGreal \\ Toronto \\ George Monckton \\ Edmonton \\ D. G. Montemurro \\ London \\ T.P. Morley \\ Toronto \\ Dwight Parkinson \\ Winnipeg \\ J. W. Phillis \\ Saskatoon \\ Louis J. Poirier \\ Quebec
}

\section{Editor}

R. T. Ross
Winnipeg

all captions should be typed on a separate piece of paper.

Colored illustrations cannot usually be accepted unless the author is prepared to assist with the cost of reproduction.

REFERENCES to authors outside the context of the sentence should read (Name, Year). i.e. "However, a recent study (Bird and Iverson, 1975) showed a decreased, etc." Authors mentioned within the context of the sentence should read Name (Year). "i.e. ... twenty years since Ecker and Reimenshender (1951) demonstrated, etc." References should be typed in alphabetical order on a separate sheet and include author's name, initials, year, title, publication, volume, first and last page, i.e. Isacson, P. (1967). Myx-oviruses and autoimmunity. Progress in Allergy, 10, 256-292. Abbreviations should be the same as those used in Cumulated Index Medicus.

Textbook references should include name of text, author's name, page number, publisher and city.

REPRINTS: Fifty reprints will be supplied free if ordered when the galley proofs are returned. More may be ordered at a nominal charge. Corrections and changes in the galley proofs, apart from printer's errors may be charged to the author.
Frank B. Walsh

Baltimore

\section{Editorial Assistant \\ Angela B. Ross \\ Winnipeg}

This journal is indexed by Index Medicus, Excerpta Medica and Current Contents - Clinical Practice and Life Science.

SUBSCRIPTIONS: This journal is issued four times a year. The annual rate is $\$ 24.00$ for Canada and the U.S.A., $\$ 26.00$ elsewhere. Internes, Residents, Preand Post-Doctoral Students, $\$ 12.00$ per annum. Single copies $\$ 10.00$ each.

ADVERTISING: Enquiries regarding advertising space and rates should be directed to LEX LTD. VANCO PUBLICATIONS, 190 Main Street, Unionville, Ontario L3R 2G9. Telephone - (416) 297-2030.

All communications, manuscripts, subscriptions, etc., should be sent to the Editor, at 700 William Avenue, Room GF543, Winnipeg, Manitoba R3E 0Z3 Canada.

COPYRIGHT ' 1978 by THE CANADIAN JOURNAL OF NEUROLOGICAL. SCIENCES INC. No part of this journal may be reproduced in any form without the prior permission of The Canadian Journal of Neurological Sciences.

Printed by Lawson Graphics Ltd., 708 Moray Street

Winnipeg, Manitoba R3) 359.

Mailed under second class registration number 3307. Postage paid at Winnipeg, Manitoba. 
Goose Quills and Burr Holes - Frank Turnbull . .

The Neurological Complications of Brucellosis

A. Larbrisseau, E. Maravi, F. Aguilera, J. M. Martinez-Lage ............................. 369

Automatic Quantitative Analysis of the Electromyogram in Partially Denervated Distal Muscles:

Comparison with Motor Unit Counting - A. J. McComas and R. E. P. Sica . . . . . . . . . . . . . . . . 377

Clinical Efficacy of Valproic Acid in Relation to Plasma Levels

J. Bruni, B. J. Wilder, L. J. Willmore, H. J. Villarreal, M. Thomas, L. E. M. Crawford ........... 385

A Comparative Study of $b$ - and $d$ - Waves of the Electroretinogram in Frogs

(Rana Catesbeiana) - S. Molotchnikoff and F. Guertin-Laurin

Accumulation and Removal of $\mathrm{Hg}^{203}$ in Different Regions of the Rat Brain

R. F. Butterworth, M. Gonce and A. Barbeau

Ouabain Induced Stereotyped Behavior in Rats

D. L. W. Davidson, R. F. Butterworth, F. Belanger, A. Barbeau

Ouabain Induced Seizures: Site of Production and Response to Anticonvulsants

Duncan L. W. Davidson, Yasuo Tsukada, Andre Barbeau

Increased Dependence on Visual Information for Movement Control in Patients with Parkinson's Disease - J. D. Cooke, J. D. Brown and V. B. Brooks

Functional Implications of Changes in the Senescent Brain: A Review - Charles H. M. Beck

Virology and Histopathology of the Trigeminal Ganglia of Americans and Japanese

K. G. Warren, Z. Wroblewska, H. Okabe, S. M. Brown, D. H. Gilden,

H. Koprowski, L. B. Rorke, J. Subak-Sharpe, and T. Yonezawa

Pseudotumor Cerebri - F. L. Moffat

Alterations of Membrane Phosphorylation in Erythrocyte Membranes from Patients with

Duchenne Muscular Dystrophy - J. D. Vickers, A. J. McComas, and M. P. Rathbone ..........437

Cerebral Tissue Response to Electrode Implantation - Ronald F. Dodson, L. W-F. Chu, N. Ishihara .... 443

Case Report and Ultrastructural Study of Intracranial

Embryonal Carcinoma - Gershon Ejeckam, Margaret G. Norman and Leslie P. Ivan ............ 447

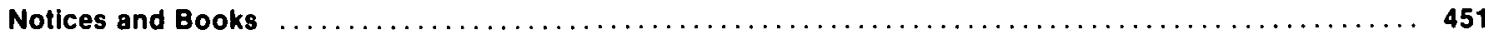

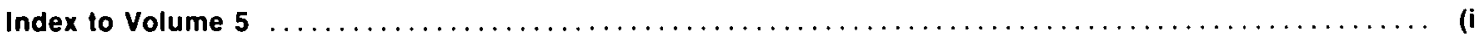




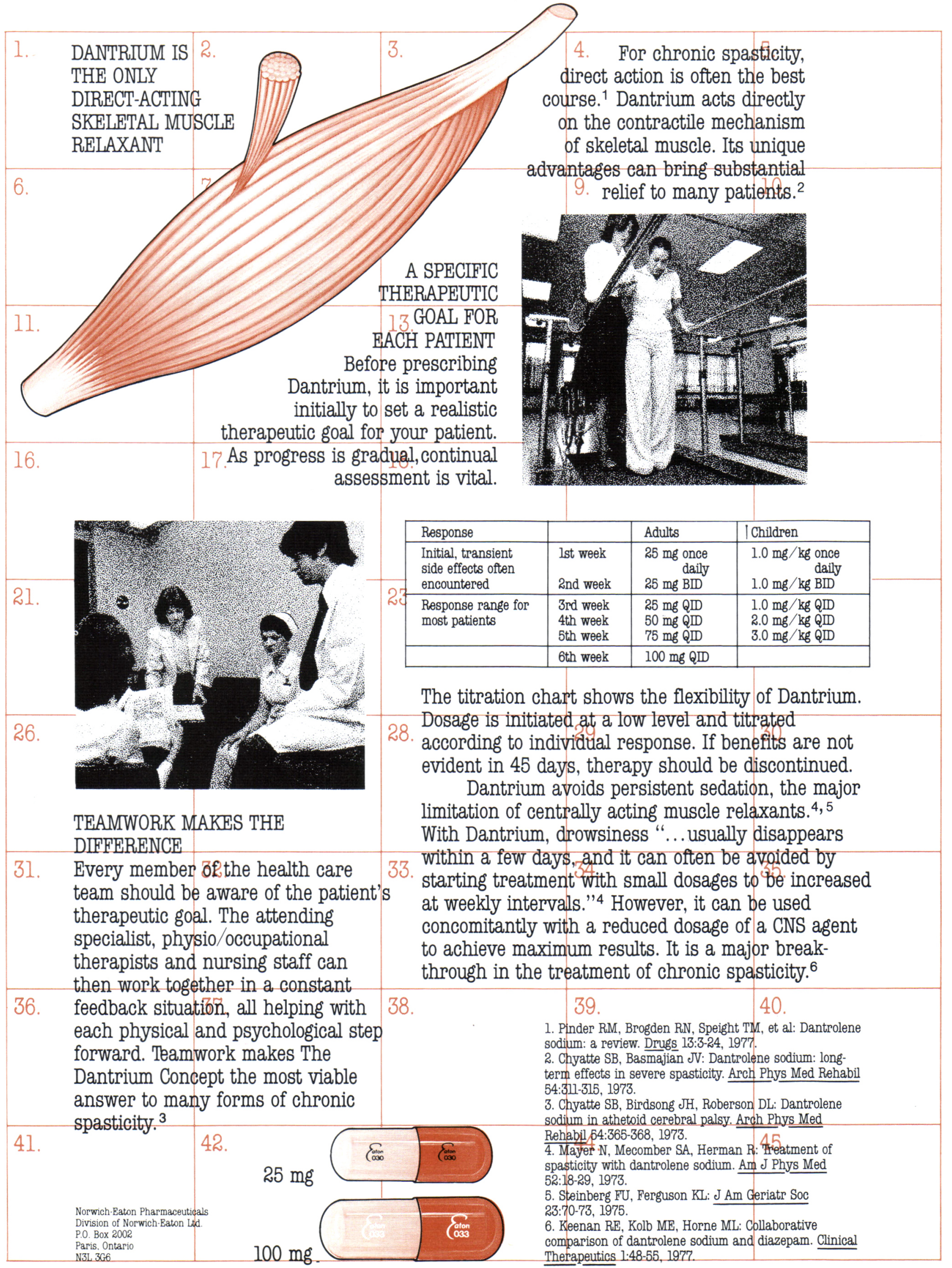

(vii) 
ACTIONS

ecordings of muscle tensions and electrical activity in both animal and man suggest that Dantrium has a direct inhbbitory effect on the develooment of contractile tension. Spastic patients receiving Dantrium have sh the skeletal muscle tension induced by direct electrical stimulation of the motor nerve with no alteration of the EMG. This decrease in contractile tension can be attributed to an effect of Dantrium beyond the myoneural junction. Total magnitude The reduction in contractile activity accounts for the ability of Dantrium to diminish spasticity resulting from

Dantrium also produces central nervous system effects resulting in such manilestations as drowsiness, dizziness and generalized weakness

in slow, dose-related blood levels are obtained which peak in 4 to 6 hours after a single oral dose. the peak anarmacolooic effect generally occurs in 112103 hours at concentrations of 501075 percent of the peak plasma level. Dantrium is highly bound to plasma protein and, 10 a lesser extent, red blood cells Metabolism is rapid via hepatic microsomal enzymes. The major metaboltres in humans are a 5-hydroxy analog and an acetamino analog. Urinary excretion period Dantrum is also removed by biliary excretion

\section{INDICATIONS}

Dantrum is usetul in controlling the manifestations of chronic spasticity of skeletal muscle resulting from such conditions as spinal cord injury. ceretral palsy. muitiple sclerosis, and stroke. whenever such spasticity results in a decrease in functional

\section{CLIMICAL USES}

Dantrium has been studied in the treatment of selected patients with moderate to severe skeletal muscie spasticity resulting from slroke, spinal cord injury, cerebral patsy. mulfiple sclerosis, and other neuropathies. It seems to act directly on the skeletal muscle and has been found usetul whenever manitestations of spasticity such as increased muscular
resistance to stretch, clonus, and exaggerated reflex posturing interfere with therapeutic exercise programs, utilization of races. uranster manoeuvres. posture equilibfium. ambulation. and activities of daily living.

Marked reduction or even cessation of spontaneous involuntary movements was obsevved in many patients receiving tested by withdrawing the drug for 2104 days and observing whether an exacerbation of the patient's condition occurs.

\section{CONTRAINDICATIONS}

Skeletal muscle spasticity without suitable volitional activity [residual motor activity) may be of value in a rehabilitation program aimed toward sustaining upright posture and balance. and may assist a patient's locomotor pattern. Reliet of such spasticity would reduce rather than increase function. Theretore. in cases where spasticity is uilized to obtain or maintain disease

DANTRIUM IDANTROLENE SODIUM! HAS THE POTENTIAL TO PRODUCE HEPATOTOXICITY AND SHOULD NOT BE USEO IN CONOITIONS OTHER THAN THOSE RECOMMENDED. CASES OF FATAL HEPATIIIS HAVE BEEN REPORTED IN PATIENTS WHO HAD RECEIVED DANTRIUM FOA SIXTYY OAYS OR LONGER. SYMPTOMATIC HEPATITIS AND LABORATORY VVIDENCE OF LIVER DYSFUNCTION HAVE AL SO BEEN REPORTED IN A NUMBER OF PATIENTS RECEIVING DANTRIUM.
SOME CASES OF HEPATITIS WERE CONSIDERED TO BE DIRECTLY RELATED IO DANIRIUM AOMINISTRATION. WHEREAS OTHERS MAY HAVE BEEN DUE IO OTHER CAUSES. OANIRIUM-INDUCEO HEPATOTOXICITY APPEARS IO PAE-EXISTING LIVER DYSFUNCTIONS NO SERIOUS HEPATIC INJURY HAS YET BEEN REPORTED IN PATIENIS HEPATIC INJURY APPEARS TO BE GREATER IN FEMALES AND IN PATIENTS OVER 35 YEARS OF AGE. THEREFOAE, BEFORE AND THROUGHOUT TREAIMENI, INCLUDING FREOUENT DEIERMINATIONS OF SERUM LIVER ENZYMES ARIAL ADMINISTRATION OF DANTRIUM IS RECOMMENDED AND IF AFTER 45 OAYS NO OBSERVABLE BENEFIT IS EVIDENT, OANTRIUM SHOULD BE DISCONTINUED. THE LOWEST POSSIBLE EFFECTIVE DOSE FOR THE INDIVIDUAL TOXICITY STUDIES IN ANIMALS PROVIDED EVIDENCE OF LOW-GRADE CARCINOGENIC ACTIVITY OF DANTRIIM IN HUMANS CANNOT BE DISREGARDEL THEREFORE THE POTENTIAL BENEFIIS OOF THE ORUG SHOULD BE WEIGH AGAINST CANNOT BE OISREEGARDED. THEREFORE. THE POTENTIAL BENEFIIS OF THE ORUG SHOULD BE WEIGHED TO WHETHER THE PATIENT HAS RESPONDED TO OTHER MEDICATION AND TO THE BENEFIIS OF THE TRIAL
ADMINISTRATION OF DANTRIUM AS AECOMMENDED ABOVE IN ASSESSING RISK ACCEPTABILITY THE AGE OF THE AOMINISTRATION OF DANTAIUM AS RECOMMENDED ABOVE. IN ASSESSING RISK ACCEPTABILITY. THE AGE OF THE PATIENT. THE OEGREE OF DISABILITY AND LIFE EXPECTANCY SHOULD ALSO BE CONSIDERED. LONG TERI
AND OTHER ASPECIS OF THE LONG TERM SAFETY OF DANTRIUM HAVE NOT YET BEEN ESTABLISHED.

Uso In Children: in view of the preceding warning, it is particularly important 10 assess risk acceptability vetore Dantrium is

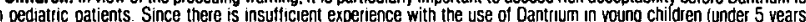
of age), the drug is usually not recommended in this age group. in such patients it should be given only when the potential benefits have been weighed against possible hazard to mother and child Dantrium stould not be used in nursing mothers

\section{PRECAUTIONS}

Although subjective weakness attributabte to Dantrium is usually transient. some patients teel excessively weak as lang as Dantrum therapy is continued. Such patients may not be able to manipulate rehabilitation devices such as wheelchairs,

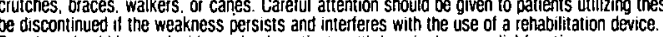

Dantrium should be used with caution in patients with impaired myocardial function

atients should be instructed not 10 drrve a motor vehicle of participate in a hazardous occupation during the first week of Dantrium therapy Although the primary pharmacologic eftect of Dantrium is exerted directly on skeletal musccle, an apparent
Iransient CNS eftect also may exist. Theretore. caution should be exercised in the concomitant administration of tranauilizing agents

Although photosensitization has not been a problem in clinical trials of Dantrium it is pessible that in some subjects the drug might evoke a phototoxic response.

The possibility of cross-sensitivity with compounds of related chemical structure exists, however, no such reactions were in long-term therapy. periodic clinical laboratory evaluation of organ systems, including haenatopoietic, renal, and hepatic studies, should be performed

AOVERSE REACTIONS
Side eftects most trequently reported were drowsiness, weakness, dizziness, malaise. fatigue and diarnhea. Less commonly reported ettects are listed by systems:

Gestrolntestinal: constipation, anorexia, gasific ifritation and bleeding, abdominal cramps. swallowing difficulty, nausea

with or without vomiting and liver tailure.
CNS: speech and visual disturbances, seizure, headache. lightheadedness, taste alterations, mental depression, confusion, ervousness, diplopia, insomnia

Urogenital: increased usinary frequency, crystalluria, difficult erection, urinary incontinence and/or nocturia, difficutt urination and/or urinary retention.

Integumentary: acne-like rash, pruritis, urticaria, eczematoid eruption, abnormal hair growth, sweating.

Other: chills, fever, excessive tearing, feeling of suttocation. ADVISABLE TO PERFORM LIVER FUNCTION TESTS BEFORE AND DURING THERAPY. ISEE WARNINGSIS

Side effects listed as most trequently occurring were generally transient and may be avoided with initial low doses and a gradual increase to optimal doses. biathea may be of sufficient severity to warrant temporany or possibly permanent

\section{SYMPTOMS ANO TREATMENT OF OVEROOSAGE}

A single case has been reponted of a patient with an 18 -year history of multiple sclerosis who consumed $1600 \mathrm{mg}$ of Dantlum per day for 13 days a total of 20,800 mgl. Other than feeling slightly weaker and "rubbery", the patient appeared to

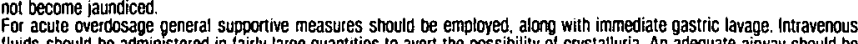
flurids should be administered in fairly large quantities to avert the possibility of crystalluria. An adequate airway should be the patient carefully observed. No experience has been reported with dialysis, hence its value in Dantrium overdosage
Chemical Name: 1-[5-10-nitrophenyl)-furfurylidene $]$ amino hydantoin sodium hydrate.

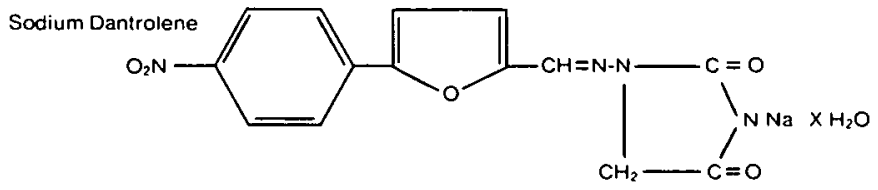

Dantrium causes marked, dose-dependent skeletal muscle relaxation in laboratory anımals with a long duration of action. The pharmacologic profile of Dantrium in animals is unlike neuromuscular blocking agents in that cotal muscle paralysis There is a wider margin between doses causing muscle retaxation and doses causing motor incoordination with Dantrium than with centrally acting muscle relaxants. Skeletal muscle relaxation is not associated with anaesthetic or analgesic action. Impairment of cornea of pinna reflexes has not been observed in animals treated with Dantrium.

various studies both in vivo and in vitro demonstrated the apparent selectivity of action of Dantritum for skeletal muscle. muscle in doses which cause skeletal muscle relaxation. Nerve transmission was nol affecled by Dantrium in several animal studies.

It has been shown that Dantrium has no effect on the propagated action potential recorded on the muscle membrane. and the total membrane capacitance is not decreased by the drug, indicating that it does not distupl the function of the transverse tubular system, and acts at a point beyond the electrically excitable surtace membrane. Evidence obtained in vitro with muscle preparations exposed to calfeine, an agent known to cause muscle contractions by releasing internal Catt stores
in muscle, suggests that Dantriumm acts on skeletal muscle by altering the Catt release mechanisms. Such an action

Animal studies have indicated that Dantrium is metabolized by hydrolysis, hydroxylation, nitro reduction and aceiylation of the resulling amine.

Four corresponding metabolites have been identified which probably do not contribute signiticantly to the activity of Dantrium. Maximal blood levels following oral administration are reached in approximately 1 hour. In dops approximately 40\% of an IV. dose of Dantrium is excreted as the hydroxylated metabollte in bile whereas only $1 \%$ of the dose Is excreted in this manner by the rat. High biliary concentrations of this metabolite have also been lound in the Rinesus monkey.
Total excretion of known metabolites in the urine is estimated at approximately $3 \%$ in the dog and approximately $10 \%$ in the rat.

\section{TOXICOLOGY}

he oral $\mathrm{LO}_{30}$ of dantrolene sodium in newborn, Sofague-Dawley rats was $2902 \mathrm{mg} / \mathrm{kg}$. No voung adult rats were killed with doses up to $18,000 \mathrm{mg} / \mathrm{kg}$. Pertinent clinical signs were inactivity, lethargy, weakness, gasping. diarthea, yellowing of pelvic necrosis occurred in kidneys. No deaths occurred within 48 hours in adult rabbils and mice. with oral doses up to 8 or $9 \mathrm{~g} / \mathrm{kg}$, respectively. Crystals were observed in the urinary and ine gall bladders of rabbits

Three subacute toxicity studies were conducted in rats with oral doses up $10500 \mathrm{mg}$ of dantrolene sodium $/ \mathrm{kg}$ for 28 days and up $1086 \mathrm{mg} / \mathrm{kg}$ for 88 days. Body weight gains were reduced signiticantly by doses o1 $43.8 \mathrm{mg} / \mathrm{kg}$. Relative kidney and liver weights were increased by doses of $15.5 \mathrm{mg} / \mathrm{kg}$ and absolute liver weights by $86 \mathrm{mg} / \mathrm{kg}$ for 88 days. Incleased
serum alkaline phosphatase and $S 60 \mathrm{OI}$ oceured with doses of $62.5 \mathrm{mg} / \mathrm{kg}$. Rats dosed with $500 \mathrm{mg} / \mathrm{kg}$ lor 28 days had increased serum alkaline phosphatase, SG0I. fasting plasma glucose, plasma urea nitrogen, serum creatinine, and
decreased urine specitic gravity. Renal lubules were plugged by orug crystals, and tubular dilatation, degeneration, necrosis and hemaluria resulted.

Chronic ioxicity sludies were conducled in Beagle dogs tor 1 year. Oral doses of $15 \mathrm{mg} / \mathrm{kg} /$ day produced no detectable etfects. At $30 \mathrm{mg} / \mathrm{kg} /$ day, there was a suppresion of weight gain and sporadic increases in BSP retention. A regimen of increasing doses $190 \mathrm{mg} / \mathrm{kg}$ for the first 206 days followed by $180 \mathrm{mg} / \mathrm{kg}$ for 14 days and $360 \mathrm{mg} / \mathrm{kg}$ for an additional
82 days) caused marked loss in body weight, increased SGOT activity and BSP retention. normocytic orthochronic 82 days) caused marked loss in body weight, increased SGOI activity and BSP retention, normocytic orthochromic after discontinuation of drug administration.

A one-year oral toxicity study also was conducted with Rhesus monkeys "Initial doses of 0.15 .30 and $60 \mathrm{mo} / \mathrm{kg}$ were used. Because of the lack of clinical toxicity during the first 6 months, the dosage levels were doubled at the end of the first 6 months. At 9 months, the dosage level for the high dose group was again doubled and these animals were inen maintained on $240 \mathrm{mg} / \mathrm{kg} /$ day until the termination of the study. A dose-dependent lowering of body weight gain was observed at 12 months. Urinary crystals were noted in one animal at the middle $160 \mathrm{mg} / \mathrm{kg}$. dayl dosage level at 11, to 12 months. Urinalyses at 6 and 12 months also indicated a drug-related increase in blood elements. During the last a months, a genum alkaline phosphatase, a high SGOr level in the iwo high dosage levels. and relatively lower serum creatinine levels in the high dosage groups were noted. Chronic nepatic cholangitis was observed at necropsy in some mid and high dosage level animals.

Dantrolene sodium was administered in the diet to mature Sprague. Dawley rats 1018 months at levels of 15.30 and $60 \mathrm{mg} / \mathrm{kg}$ daily. Treated rats showed a lower body weight gain compared to controls and damage to the liver. There was an
increase in the incidence of mammary adenotibromas in the lemales. Other drug-related changes iseen only at the 30 and $60 \mathrm{mg} / \mathrm{kg}$ daily dosage levels\} were increased incidences of bile duct cystadenomas, and increased signs of malignancy in mammary tumors in temales. At the $60 \mathrm{mg} / \mathrm{kg}$ daily level the number of metastasizing mammary adenocarcinomas in lemale rats was increased significantly; anisotropic usinary crystals were found in both male and fernale groups. treated Sprague-Dawley rats received dantrolene sodium in the diet at levels of 15.30 and $60 \mathrm{mg} / \mathrm{kg}$ dally for 18 months and the Fischer 344 rats received the same levels for 20 months. The animals subsequently were maintained on a standard diet until $90 \%$ of each treatment group died spontaneously. Dantrium produced in the temale Sprague-Dawley rats a linear, dose-related increase in the number of rats with malignant neoplasms. and a decrease in the time of onset of mammary neoplasms. There were also increased incidences of benign hepatic tumors including lymphangiomas and bile duct
cystadenomas, and angiosarcomes. In Fischer rats, there was a signiticant. dose-related reduction in the times of onset of
mammany and testicular fumors.

A two year tumorigenesis study was conducted in Swiss mice (CD*-1 HaM/ ICR). Dantrolene sodium was fed to mice at 列 then the mice were maintained on a stand 作 was an increased incidence of benign anglomatous necolasmsEftects on Reproductlon: Dietary doses of 0.15 or $45 \mathrm{mg}$ of dantrolene sodium $/ \mathrm{kg}$ o1 body weight were given to rats and
rabbits in classical reproductive and teratogenic studies. Significant untoward effects were not observed One litter of 14 pups from a rat treated with $45 \mathrm{mg}$ of dantrolene sodium/ $\mathrm{kg}$ between days 6 to 15 of gestation had 6 malformed pups. Maliormations included kinky tails. a short upper jaw. and renal agenesis. Iwo pups in another litter had unilateral dosage and aDmimistration

Prior to the administration of Dantrium, consideration should be given to the potential response to treatment. A decrease in spasticity sufficient to allow a daily function not otherwise attainable should be the ther aper
Dantrium. Refer to section on "Clinical Uses" for description of possible areas of response.

It is important to establish a thesapeutic goal fregain and maintain a specific lunction such as therapeutic exercise program, utilization of braces, transfer manoeuvres. elc.) betore beginning Dantrium therapy. Dosage should be increased untit the maximum pertormance compatible with the dysfunction due to underlying disease is achieved. No further increase
in dosage is then indicated. Usual bosage: it is important that the dosage be titrated and individualized for maximum effect. The lowest dose Adults: Beoin therapy with $25 \mathrm{mg}$ once daily; increase to $25 \mathrm{mg}$ two thee or four times daily and then, oy increments of $25 \mathrm{mg}, 10100 \mathrm{mg}$ two, three, of four times daily. if necessary. Each dosage level should be maintained for four to seven days, depending on the patient's tolerance, and should be increased only if the therapeutic goal has not been attained.
Only occasionally will a dose greater than $100 \mathrm{mo}$ four times daily be required in which case the dose can be increased Only occasionally will a dose greater than io0 $\mathrm{mg}$ four times daily be required in which case the dose can be increased gradually, depending on tolerance, up to $200 \mathrm{mg}$ tour times daily.
The dose shoutd not be increased beyond. and may even have to be reduced to, the amount at which the patient received maximal benefit without adverse eltects.
Childsen: A similar approach should be utilized. stanting with $1.0 \mathrm{mg} / \mathrm{kg}$ of body weight once dally. this is increased to $1.0 \mathrm{mg} / \mathrm{kg}$ two, three, or lour times daily and then, by increments of $0.5 \mathrm{mg} / \mathrm{kg}$, up $103.0 \mathrm{mg} / \mathrm{kg}$ two, three, or four times daily if necessary. Each dosage level should be maintained tor four to seven days depending on the patient's tolerance. and should be increased only if the in
should not be used in children.

DOSAGE FORMS

Dantrium is available in opaque orange and hroun capsules of $25 \mathrm{mg}$ (coded "Eaton 030" in black) and opaque orange and brown capsules of $100 \mathrm{mg}$ (coded "Eaton 033" in whitel. They are supplied in bottles containing 100 and 500 capsules. Oantrium is a registered tiademark.

Norwich. Baton Pharmaceuticals

Division of Norwich-Eaton Lid.

P.0. Box 2002

N3L 3 G6 


\section{For the management of Vertigo in Meniere's disease}

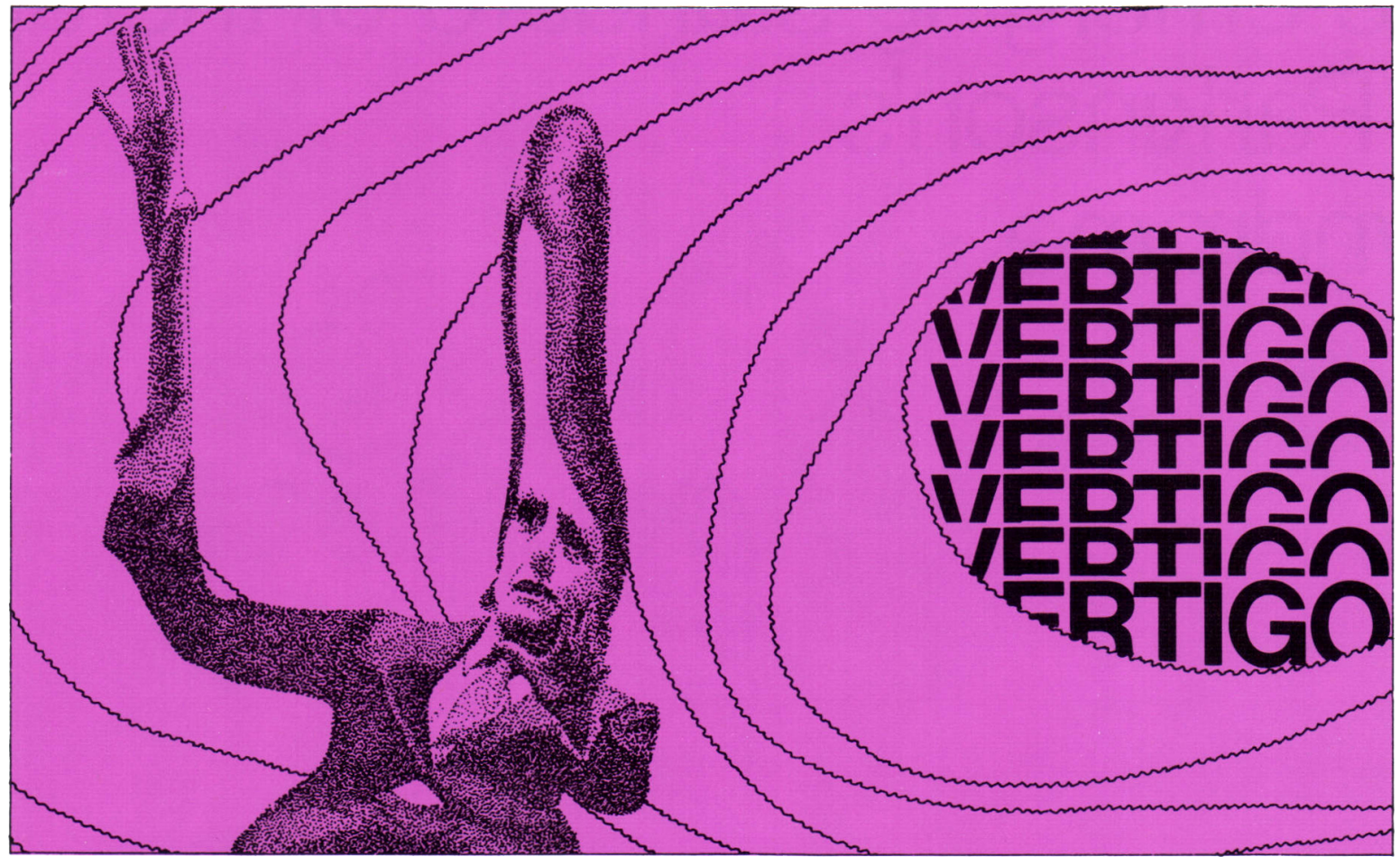

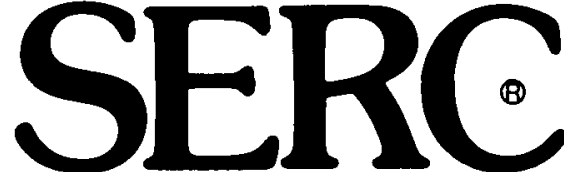

(Betahistine hydrochloride) TABLETS

\section{A decade of clinical success in Canada}

Chemically Unique

Vasoactive Compound

- Vascular responses similar to those of histaminel, 2

- Tends to restore, not depress vestibular response $e^{3,4}$

May Increase Blood Flow

To Inner Ear

- Increases cochlear blood flow in experimental animals. 5

- Increases basilar and labyrinthine artery flow in canine studies 7.8

\section{Demonstrated Efficacy and}

Patient Acceptance

- Reduces the number and severity of vertigo attacks 9.10

- Suitable for long term management ${ }^{9,10}$

-Effective when other medications failed ${ }^{9,10}$

- Well tolerated2. 3, 4, 9. 10 histaminic - not antihistaminic often a more helpful approach

REFERENCES

1. Hunt, W. H. and Fosbinder, R. J: A study of some beta-2, and 4, pyridylatkylumines J. Pharmacol. \& Exper. Ther ap. 75:299 (August) 1942.

2. Horton, B.T., and von Leden. H.: Clnical use of beta-2-pyndylalkyiamines. Pant I. Proceedungs of the Staft Meetings of The Mayo Clinc 37692 (Dec 5) 1962

3. Bertiand, R. A.. Menieres disease: Subjectrve and objective evaluation of medical treatment

4. Wim $T$. $J$ : An obective study of the eftect of betastine hydro

4. Westbular function tests in patients with Meniere's disease J hydrochloride on hearing and 5. Snow. J. B. Jr. and Suga, F.. Labyrinthine vasodilators. A.M.A. Arch. Otolaryng. $97: 365$ (May) 1973 6. Martinez, D. M.: The eftect of Serc (betahistine hydrochlonidel on the crrculatson of the inner ear in experimental animals. Acta ototaryng. Supplement 305:29, 1972.

7. AndersOn, W. D., and Kubicek, W. G.: Effects of betahistine HCI, nicotinic acid, and histamine on basilar blood flow in anesthetized dogs. Stroke 2:409 (Juty August) 1971.

Bubicen, W. G. And Ans

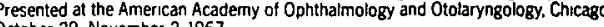

9. Cuay. R. Mencre's disease 12:25 (Augus:

10. Hommes, O. R.: A study of the efficacy of betahistine in Meniere's syndrome. Acta ototaryne. 05:70, 1972

PRESCRIBING INFORMATION

DESCRIPTION AND CHEMISTRY: SERC is the propretary name for a histaminelike drug gene ically designated as betahistine hydrochloride

INDICATIONS: SERC may be of value in reducing the episodes of vertigo in Meniere's disease. No claim is made for the effectiveness of SERC in the symptomatic treatrient of any form vertigo other than that associated with Mentere's disease each) administered orally three times a day

Recommended starting dose is two tablets three times daty Therapy is then adjusted as needed to mantan pattent response. The dosage has ranged from two tablets per day to eght tablets per day No more than elght tablets are recommended to be taken in any one day.
SERC (betahistine hydrochloride) is not recommended for use in children. As with all drugs.

CONTRINOCATIONS Se al

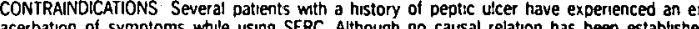
acerbation of symploms while using condition. SERC is also contrandicated in patients with pheochromocytoma
PRECAUTIONS. Although clinical intolerance to SERC by pattents with bronchal asthma has no been demonstrated. caution should be exercised if the drug is used in these pattents.

USE IN PREGNANCY: The sarety of SERC in pregnancy has not been established Therefore, its use in pregnancy or lactation, or in women of childbearing age requires that its potential benefits be weghed against the possible rists

HOW SUPPUED: Scored tablets of 4 alients have experienced gastric upset nausea and headache. bottles of 100 tablets.

UNIMED

Dorval Quebec, H9P 2P4 
(levodopa and carbidopa combination)

\section{the emerging standard of therapy} in Parkinson's syndrome

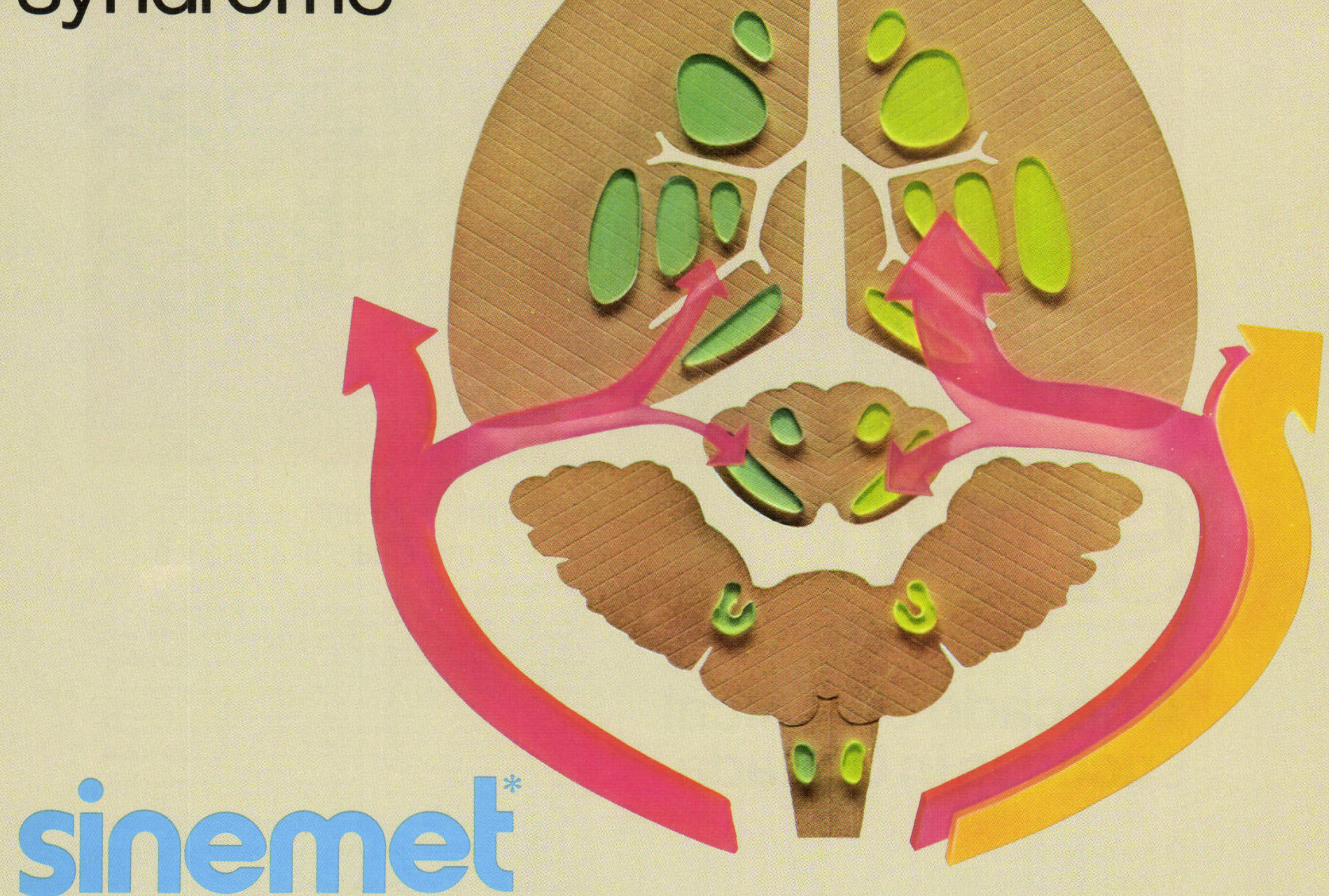

by efficiently increasing the cerebral supply of dopamine permits control of the major symptoms particularly rigidity and bradykinesia

\section{enables patients to lead more normal lives}

Common adverse reactions that can occur with SINEMET*are abnormal involuntary movements and, less frequently, mental changes. These usually can be diminished by dosage reduction. 
INDICATIONS

Treatment of Parkinson's syndrome with exception of drug induced parkinsonism.

CONTRAINDICATIONS

When a sympathomimetic amine is contraindicated: with monoamine oxidase inhibitors which should be discontinued two weeks prior to starting SINEMET*; in uncompensated cardiovascular endocrine hematologic hepatic, pulmonary or renal disease; in narrowangle glaucoma; in patients with suspicious undiagnosed skin lesions or a history of melanoma.

WARNINGS

When given to patients receiving levodopa alone, discontinue levodopa at least 12 hours before initiating SINEMET * at a dosage that provides approximately $20 \%$ of previous levodopa.

Not recommended in drug-induced extrapyramidal reactions; contraindicated in management of intention tremor and Huntington's chorea.

Levodopa related central effects such as involuntary movements may occur at lower dosages and sooner. and the on and off phenomenon may appear earlier with combination therapy.

Monitor carefully all patients for the development of mental changes, depression with suicidal tendencies, or other serious antisocia behaviour.

Cardiac function should be monitored continuously during period of initial dosage adjustment in patients with arrhythmias.

Upper gastrointestinal hemorrhage is possible in patients with history of peptic ulcer.

Safety of SINEMET * in patients under 18 years of age not established.

Pregnancy and lactation: In women of child bearing potential, weigh benefits against risks. Should not be given to nursing mothers. Effects on human pregnancy and lactation unknown. PRECAUTIONS

General: Periodic evaluations of hepatic hematopoietic, cardiovascular and renal function recommended in extended therapy Treat patients with history of convulsions cautiously. Physical Activity: Advise patients improved on SINEMET * to increase physica activities gradually, with caution consistent with other medical considerations. In Glaucoma: May be given cautiously to patients with wide angle glaucoma. provided intraocular pressure is well controlled and can be carefully monitored during therapy. With Antihypertensive Therapy: As symptomatic postural hypotension has been reported occasionally give cautiously to patients on antihypertensive drugs, checking carefully for changes in pulse rate and blood pressure. Dosage adjustment of antihypertensive drug may be required. With Psychoactive Drugs: If concomitant administration is necessary, administer psychoactive drugs with great caution and observe patients for unusual adverse reactions. With Anesfor unusual adverse reactions. With Anesbefore general anesthesia and reinstitute as soon as patient can take medication orally. ADVERSE REACTIONS

Most Common: Abnormal Involuntary Movements-usually diminished by dosage reduction-choreiform, dystonic and other involuntary movements. Muscle twitching and blepharospasm may be early signs of excessive dosage. Other Serlous Reactions: Oscillations in performance: diurnal variations, independent oscillations in akinesia with stereotyped dyskinesias, sudden akinetic crises related to dyskinesias, akinesia paradoxica (hypotonic freezing) and 'on and off' phenomenon Psychiatric: paranoid ideation, psychotic episodes, depression with or without development of suicidal tendencies and dementia. Levodopa may produce hypomania when given regularly to bipolar depressed patients. Rarely convulsions (causal relationship not established). Cardiac irregularities and/or palpitations, orthostatic hypotensive episodes anorexia, nausea, vomiting and dizziness.
Other adverse reactions that may occur: Psychiatric: increased libido with serious antisocial behaviour, euphoria, lethargy, sedation. stimulation, fatigue and malaise, confusion, insomnia, nightmares, hallucinations and delusions, agitation and anxiety. Neurologic: ataxia, faintness, impairment of gait, headache. increased hand tremor, akinetic episodes. "akinesia paradoxica". increase in the frequency and duration of the oscillations in performance, torticollis, trismus, tightness of the mouth, lips or tongue, oculogyric crisis, weakness, numbness, bruxism, priapism. Gastrointestinal: constipation, diarrhea, epigastric and abdominal distress and pain. flatulence; eructation, hiccups, sialorrhea; difficulty in swallowing, bitter taste, dry mouth: duodenal ulcer; gastrointestinal bleeding: burning sensation of the tongue. Cardiovascular: arrhythmias, hypotension, nonspecific ECG changes, flushing, phlebitis. Hematologic: hemolytic anemia, leukopenia, agranulocytosis. Dermatologic: sweating, edema, hair loss, pallor, rash, bad odor, dark sweat. Musculoskeletal: low back pain, muscle spasm and twitching musculoskeletal pain. Respiratory: feeling of pressure in the chest, cough, hoarseness, bizarre breathing pattern, postnasal drip. Urogenital: urinary frequency, retention, incontinence, hematuria, dark urine nocturia, and one report of interstitial nephritis. Special Senses: blurred vision, diplopia dilated pupils, activation of latent Horner's syndrome. Miscellaneous: hot flashes, weight gain or loss. Abnormalities in laboratory tests reported with levodopa alone, which may occur with SINEMET ${ }^{\star}$ : Elevations of blood urea nitrogen SGOT, SGPT, LDH, bilirubin, alkaline phosphatase or protein bound iodine. Occasional reduction in WBC, hemoglobin and hematocrit. Elevations of uric acid with colorimetric method. Positive Coombs tests reported both with SINEMET* and with levodopa alone, but hemolytic anemia extremely rare.

DOSAGE SUMMARY

In order to reduce the incidence of adverse reactions and achieve maximal benefit, therapy with SINEMET* must be individualized and drug administration continuously matched to the needs and tolerance of the patient Combined therapy with SINEMET* has a narrower therapeutic range than with levodopa alone therapeutic range than with levodopa alone because of its greater milligram potency. Therefore, titration and adjustment of dosage should be made in small steps and recom mended dosage ranges not be exceeded. appearance of involuntary movements should be regarded as a sign of levodopa toxicity and
an indication of overdosage, requiring dose an indication of overdosage, requiring dose
reduction. Treatment should, therefore, aim at maximal benefit without dyskinesias.

Therapy in Patients not receiving Levodopa: Initially $1 / 2$ tablet once or twice a day, increase by $1 / 2$ tablet every three days if desirable. An optimum dose of 3 to 5 tablets a day divided into 4 to 6 doses.

Therapy in Patients receiving Levodopa:

Discontinue levodopa for at least 12 hours, then give approximately $20 \%$ of the previous evodopa dose in 4 to 6 divided doses.

FOR COMPLETE PRESCRIBING INFORMATION, PARTICULARLY DETAILS OF DOSAGE AND ADMINISTRATION, PLEASE CONSULT PRODUCT MONOGRAPH WHICH IS AVAILABLE ON REQUEST.

HOW SUPPLIED

Ca 8804-Tablets SINEMET * 250, dapple-blue, oval, biconvex, scored, compressed tablets coded MSD 654, each containing $25 \mathrm{mg}$ of carbidopa and $250 \mathrm{mg}$ of levodopa. Available in bottles of 100 and 500 .

*Trademark

SNM-8-480-JA
MOVING?

PLEASE NOTIFY US OF YOUR CHANGE OF ADDRESS IN ADVANCE.

\section{PASTE OLD ADDRESS LABEL HERE}

NEW ADDRESS:

NAME:

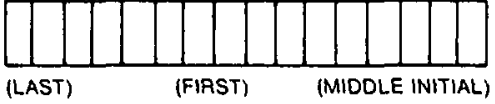

STREET ADDRESS:

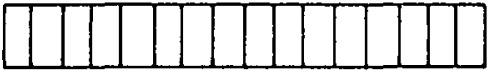

CITY:

\section{TाT}

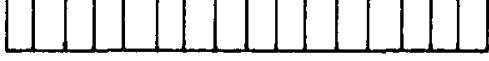

PROVINCE/STATE:

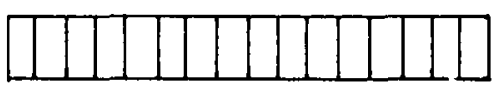

COUNTRY:

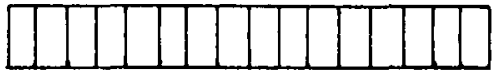

POSTAL/ZIP CODE:

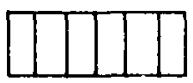

MAIL TO:

C.J.N.S.

700 William Ave., Rm. GF543

Winnipeg, Manitoba, Canada

R3E 023 


\section{INTRODUCING:}

THE DISA LINE OF

EQUIPMENT FOR

ELECTROENCEPHALOGRAPHIC STUDIES.

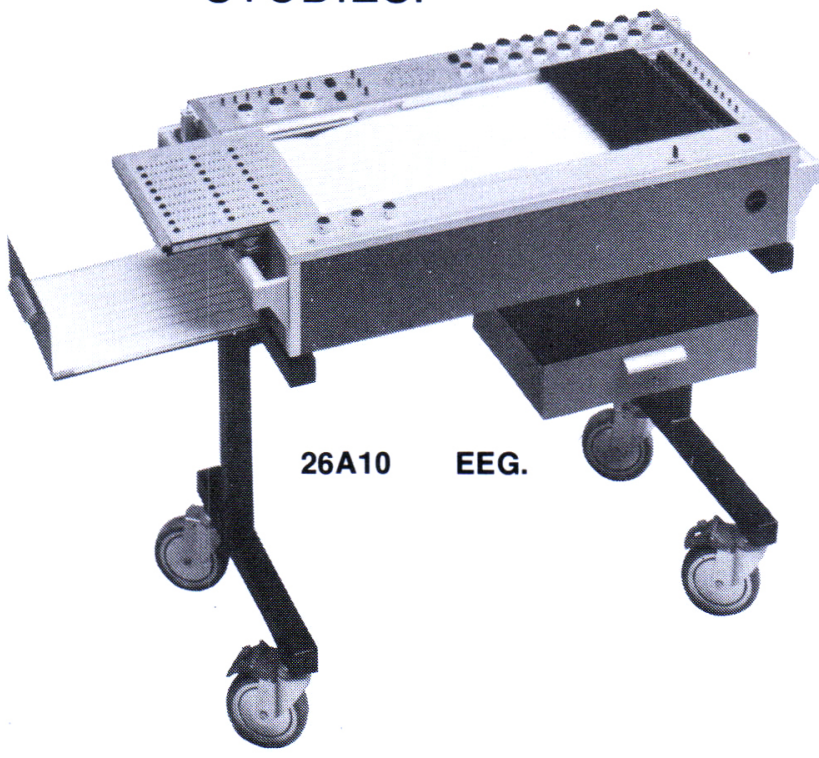

FEATURES: (All Standard)

- 8 EEG Channels

- 1 EKG Channel + 1 Marker Channel

- Average Recording

- Amplifiers in Electrode Box

- 24 Routine Lead-off Programs

- Sindex Switch

- Electronic Switches

- Automatic Electrode Resistance Indication

- Automatic Deblocking

- Nos Filter System

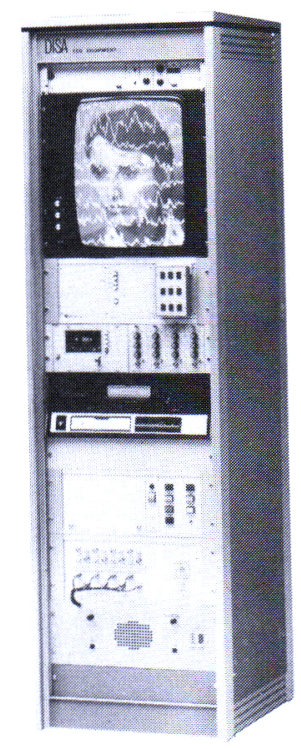

COMBINED VIDEOGRAPH \& RAPISCAN SYSTEM

In addition to Standard $8 \& 16$ Channel EEG's, DISA also produces a Large Selection of Electrodes and EEG Auxiliary Equipment.

For Example:

- Photo-Phono Stimulators

- Telemeter System

- Recorder Systems

- Videograph

- Rapiscan Systems

For further information please phone or write to:

DISA ELECTRONICS LTD., 140 Shorting Road, Scarborough, Ont. M1S 356 Telephone: (416) 298-2091 Telex: 065-25137 


\section{DIGITAL EMG SYSTEMS}

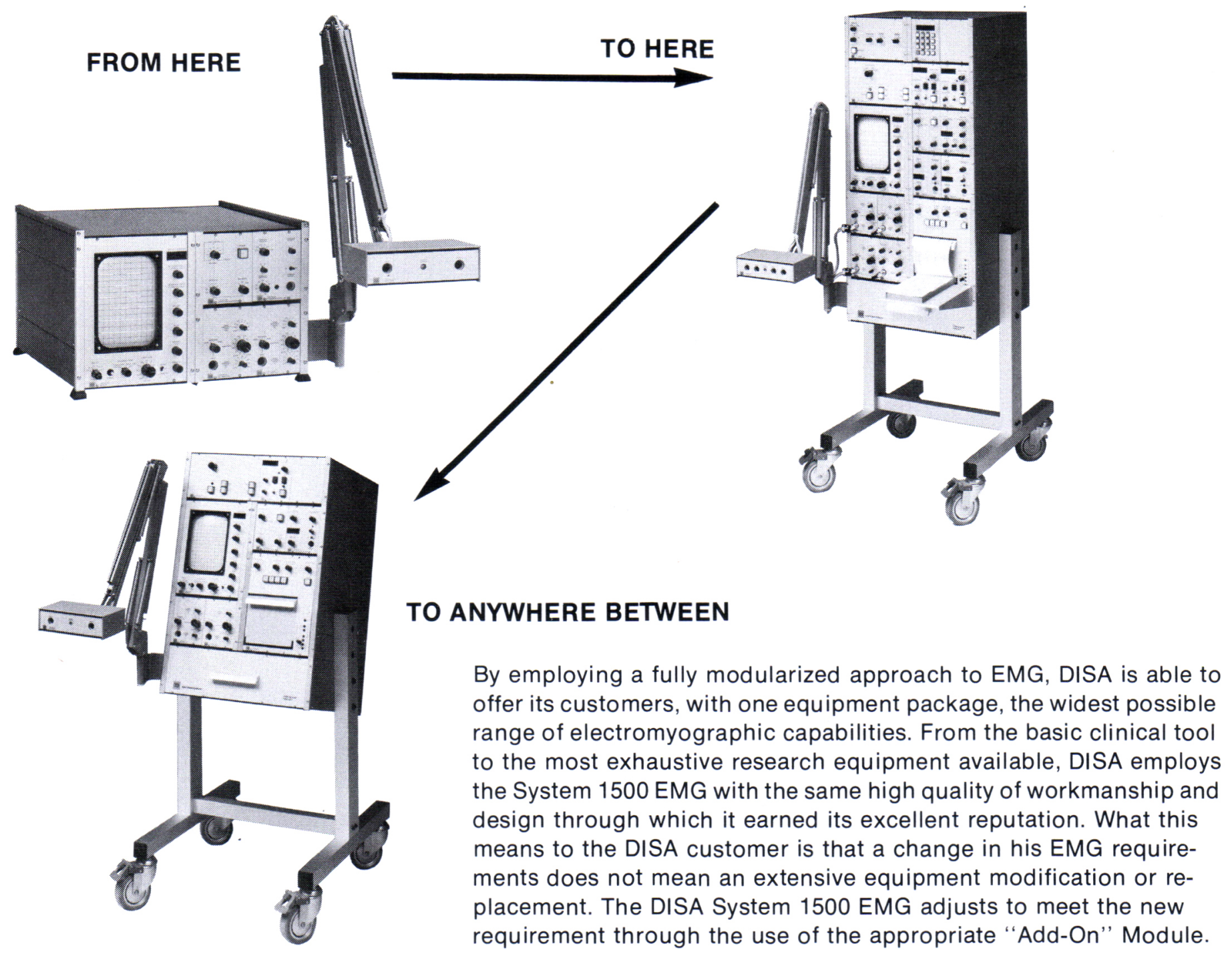

DISA has maintained its leading position in the field of EMG development through the recent presentation of the following new capabilities available as 1500 Modules:

$$
\begin{gathered}
\text { - Ultra Low Noise Sensory Amplifier } \text { Multistim Stimulator } \\
\text { Alphanumeric Data Printer } \\
\text { Interpack Module for Minicomputer Hook-Up }
\end{gathered}
$$

For further information please phone or write to:

\section{DISA ELECTRONICS LTD., 140 Shorting Road, Scarborough, Ont. M1S 356 Telephone: (416) 298-2091 Telex: 065-25137}

In USA: DISA Electronics, 779 Susquehanna Ave., Franklin Lakes, N.J. $07417 \quad$ (201) 891-9460

DISA Electronics, 4676 Admiralty Way, Suite 507, Marine Del Ray, CA 90291 


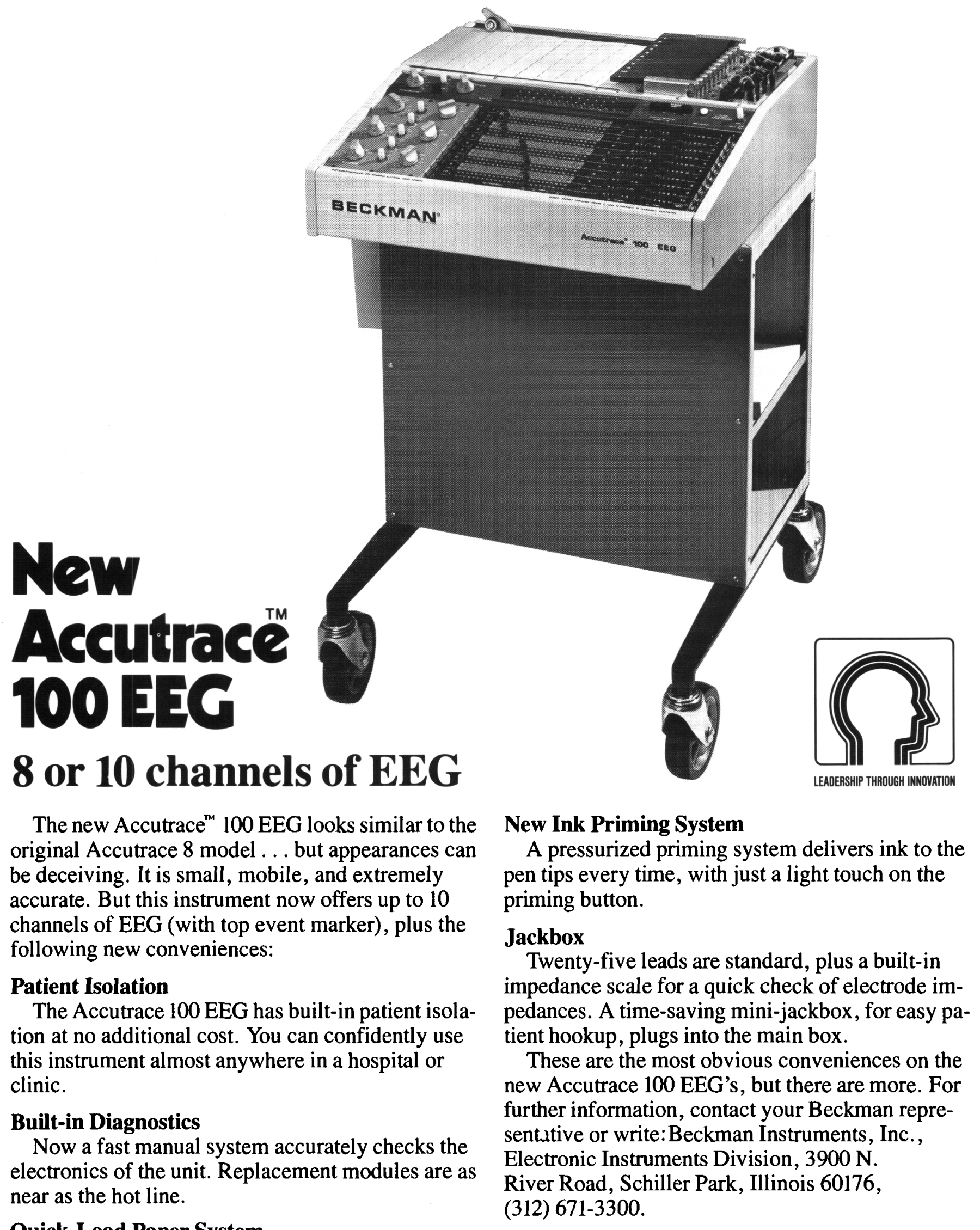

\section{Quick-Load Paper System}

Load or change chart paper in seconds with the new Accutrace paper feed system. 


\section{Prankinsonismm... an obstacle course}

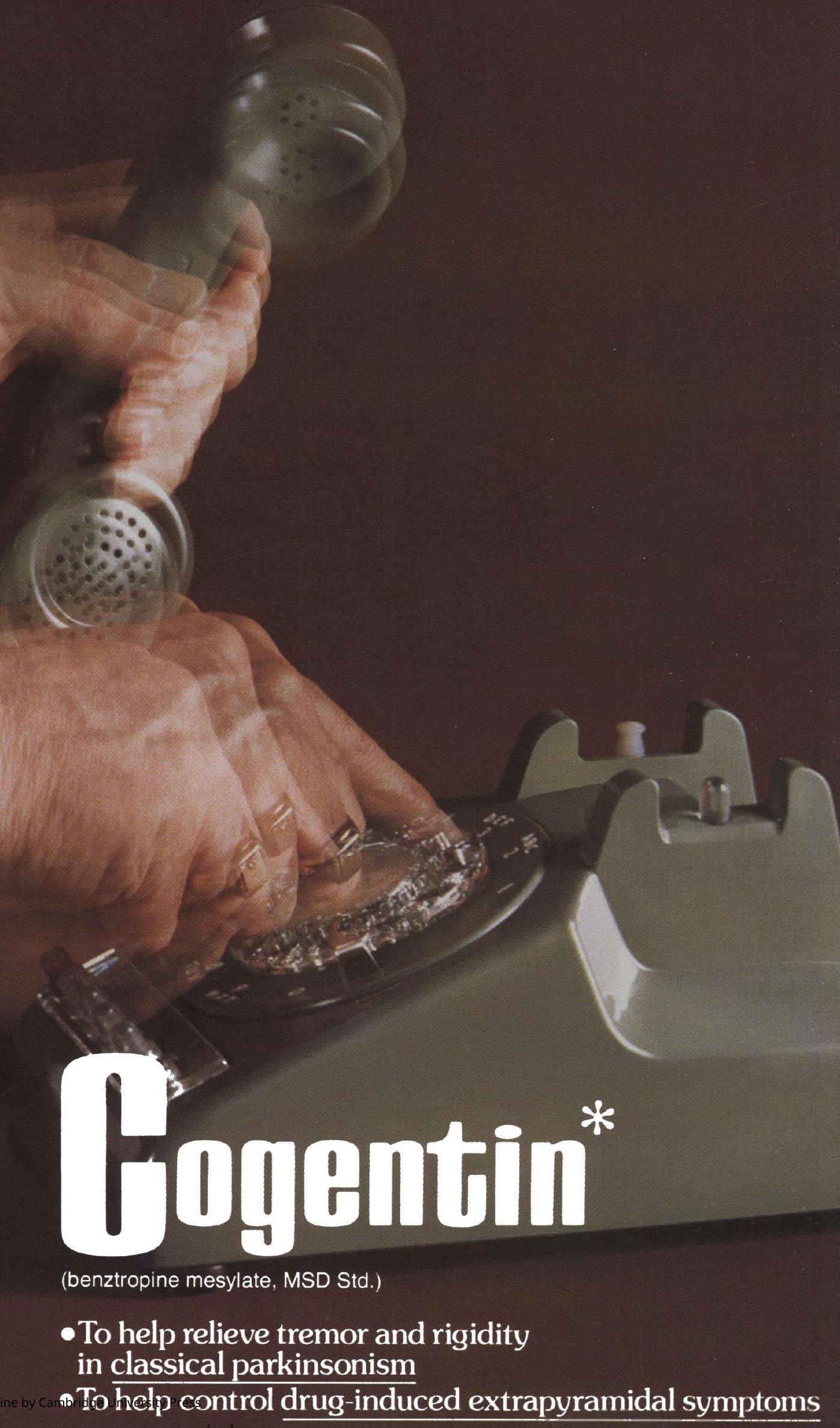


A simple task

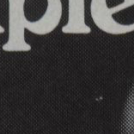

butan embarrassing moment for the patient with parkinsonism
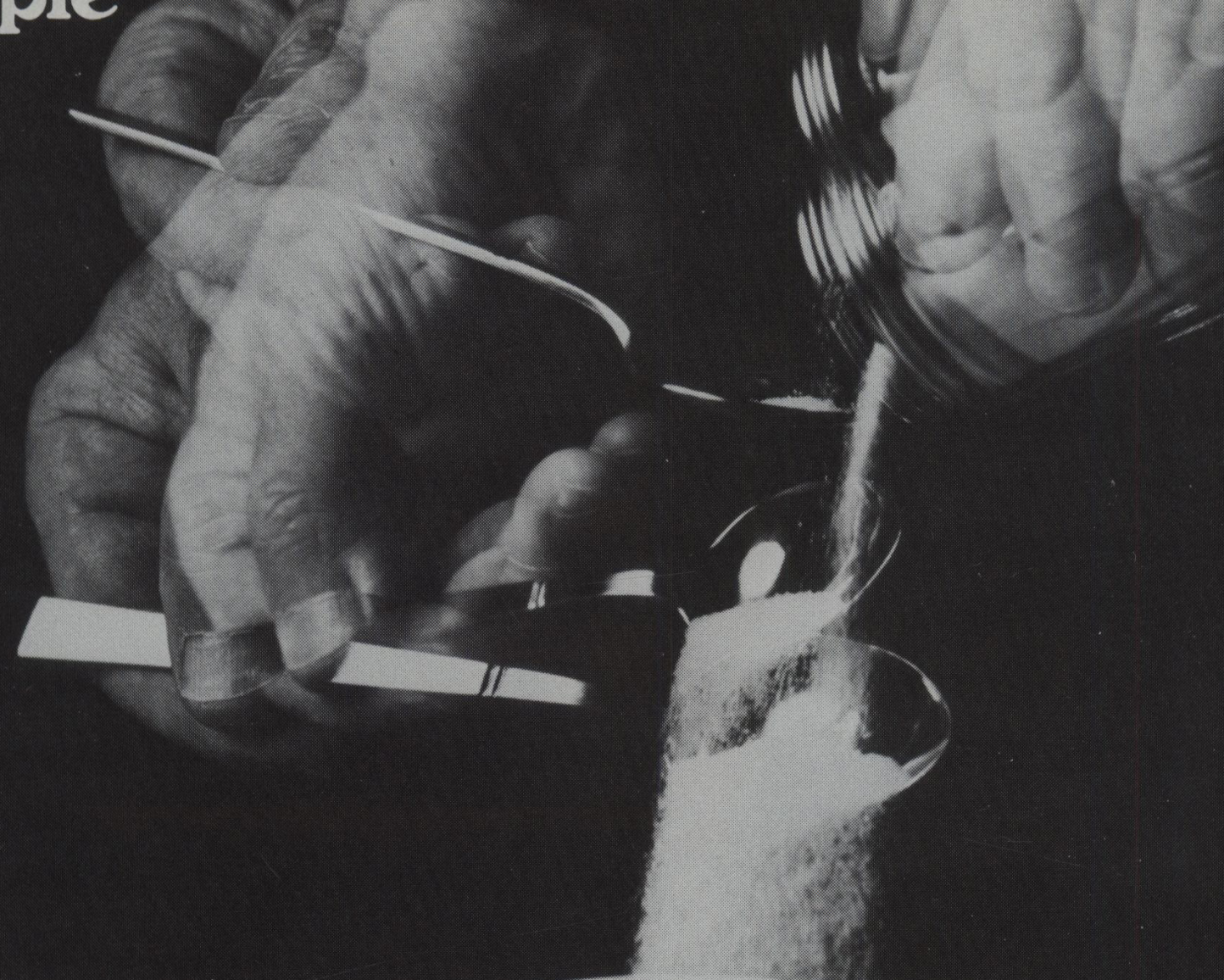

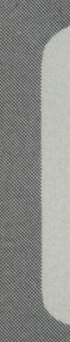
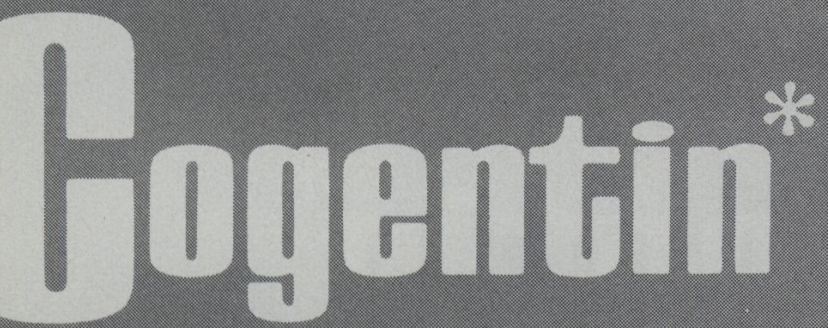

(benztropine mesylate, MSD Std.)

Antiparkinsonian agent 


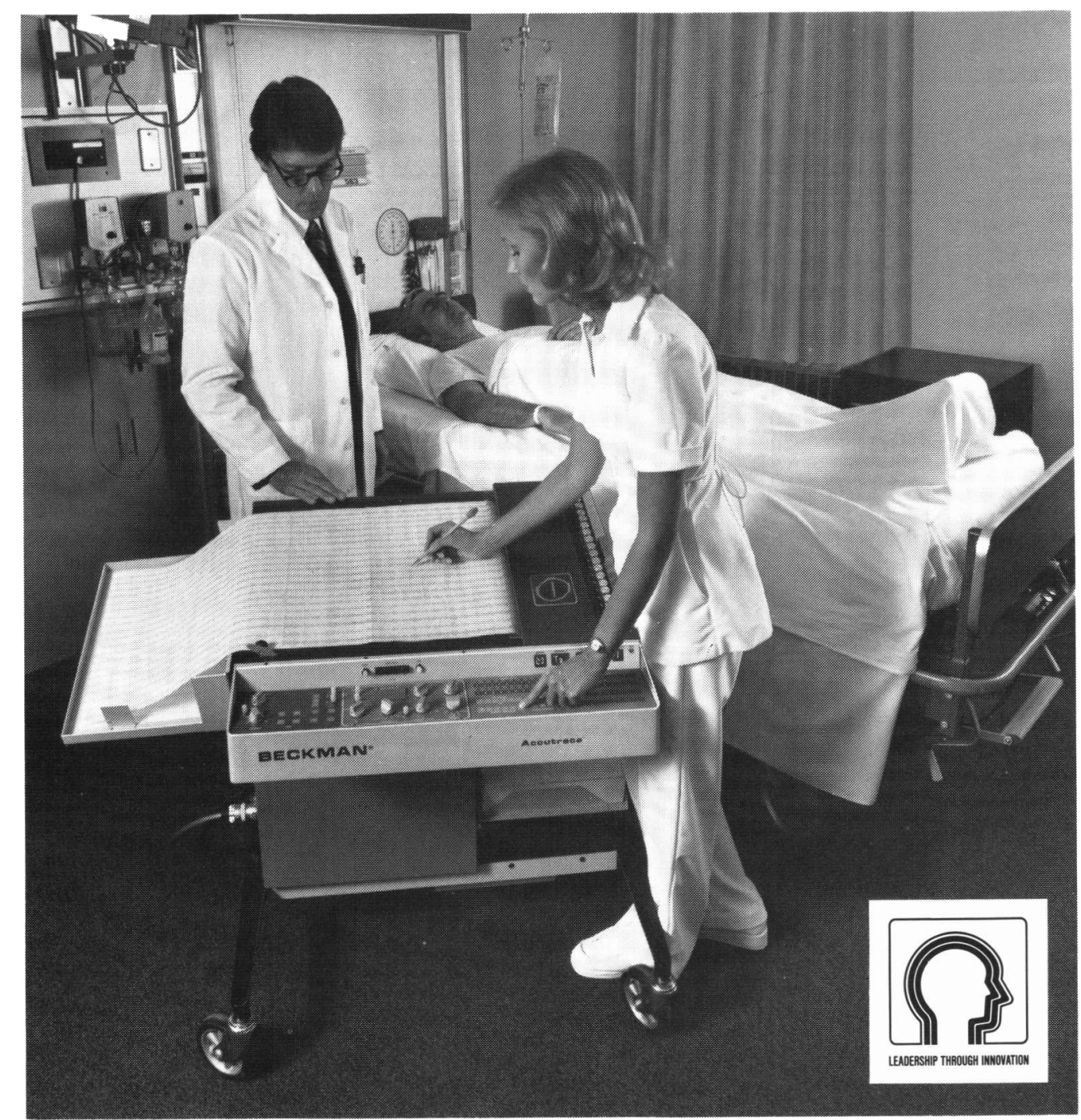

Photo taken in the ICU at Oak Park Hospital, Oak Park, Illinois.

\section{Patient isolation- convenience or necessity?}

The answer is both. It is a necessity when confronted by patients with cardiac catheters or when EEG's must be taken under less than ideal conditions, such as the ICU.

It is a convenience because you shouldn't have to worry about these situations. You should be confident your EEG can be used on virtually anyone, almost anywhere in a hospital or clinic.

With the new Accutrace ${ }^{\mathrm{TM}} 100$ and 200 EEG's, you have the confidence and conven- ience of a patient-isolated EEG. This is a standard feature and doesn't cost extra; it isn't an "add on" or an option.

This is only one of the many important reasons for selecting the Accutrace EEG. For more information, contact your local Beckman representative or write: Beckman Instruments, Inc., Electronic Instruments Division, 3900 N. River Road, Schiller Park, Illinois 60176, (312) 671-3300. 
"Erratum. The following type was unfortunately dropped from page 328 , right hand column of the August, 1978 issue, Number 3, Volume 5."

Because of these quite unexpected findings, a search of other tissues was undertaken for evidence of embolization. Similar emboli were discovered, but with more difficulty in the capillaries of renal glomeruli, myocardium and lung. None of these were associated with evidence of ischemic tissue injury. Emboli were also present in the 